\title{
Perceived Discrimination and Health: A Meta-Analytic Review
}

\author{
Elizabeth A. Pascoe and Laura Smart Richman \\ Duke University
}

\begin{abstract}
Perceived discrimination has been studied with regard to its impact on several types of health effects. This meta-analysis provides a comprehensive account of the relationships between multiple forms of perceived discrimination and both mental and physical health outcomes. In addition, this meta-analysis examines potential mechanisms by which perceiving discrimination may affect health, including through psychological and physiological stress responses and health behaviors. Analysis of 134 samples suggests that when weighting each study's contribution by sample size, perceived discrimination has a significant negative effect on both mental and physical health. Perceived discrimination also produces significantly heightened stress responses and is related to participation in unhealthy and nonparticipation in healthy behaviors. These findings suggest potential pathways linking perceived discrimination to negative health outcomes.
\end{abstract}

Keywords: perceived discrimination, health, meta-analysis, health behaviors

Supplemental materials: http://dx.doi.org/10.1037/a0016059.supp

Although the expression of outright discrimination has been greatly reduced in recent decades, more subtle and chronic forms of discrimination are still very real for certain groups in our society. A number of comprehensive literature reviews find substantial evidence-from both laboratory and community studiesfor the harmful health effects of discrimination across a range of mental health outcomes including depression, psychological distress, anxiety, and well-being (e.g., D. R. Williams, Neighbors, \& Jackson, 2003; Paradies, 2006). Perceived discrimination has also been linked to specific types of physical health problems, such as hypertension, self-reported poor health, and breast cancer, as well as potential risk factors for disease, such as obesity, high blood pressure, and substance use (see, e.g., D. R. Williams \& Mohammed, 2009, for a review).

However, none of the prior reviews of the association of discrimination to health document the quantitative nature of this relationship. The meta-analysis we present enables deeper insights than past reviews by systematically examining the strength of the evidence for the effect of discrimination on multiple health out-

Elizabeth A. Pascoe and Laura Smart Richman, Department of Psychology and Neuroscience, Duke University.

This research was supported by National Institute of Mental Health Grant 1K01-MH-074942-02 to Laura Smart Richman. Portions of this research were presented at the annual convention of the Society for Personality and Social Psychology, Albuquerque, NM, 2008. This article is based on a master's thesis by Elizabeth A. Pascoe presented to Duke University.

We would like to thank Sherman James and Redford Williams for their helpful feedback on an earlier version of this article. We also thank Anders Campbell, Devika Jutagir, Liz Victor, and Meredith McAdams for their help in coding articles for the meta-analytic portion of this research.

Correspondence concerning this article should be addressed to Elizabeth A. Pascoe, Department of Psychology and Neuroscience, Duke University, Box 90086, Durham, NC 27708-0086. E-mail: eapascoe@gmail.com comes. In addition, we tested the strength of our discrimination model in which we identify specific pathways by which health is likely to be affected. We also systematically examined whether these relationships vary on the basis of gender or race and ethnicity.

One way to understand the experience of discrimination is that it is a stressor that can broadly impact health. Although most stressful experiences do not increase vulnerability to illness, certain kinds of stressors - those that are uncontrollable and unpredictable - are particularly harmful to health, and these characteristics are common to discrimination experiences (see D. R. Williams \& Mohammed, 2009, for further discussion). Along these lines, recent research on the psychological implications of perceiving discrimination applies a stress and coping framework (e.g., Major, Quinton, \& McCoy, 2002) to understand the responses of the targets of prejudice and discrimination. Similarly, physical health outcomes linked to discrimination have also been characterized as a stress response (e.g., Clark, Anderson, Clark, \& Williams, 1999). These models conceptualize discrimination as a social stressor that sets into motion a process of physiological responses (e.g., elevated blood pressure, heart rate, cortisol secretions), and these heightened physiological responses over time can have downstream effects on health. Ambulatory blood pressure studies indicate that perceived racism may influence cardiovascular disease risk through its effects on nocturnal blood pressure recovery (Brondolo et al., 2008) and higher systolic and diastolic blood pressure throughout the day (Steffen, McNeilly, Anderson, \& Sherwood, 2003). General perceived discrimination (i.e., not necessarily race based) has also been found to predict steeper systolic blood pressure trajectories over the course of the day (Smart Richman, Pek, \& Pascoe, 2008). These findings are important because numerous studies have found that exaggerated cardiovascular responses to stress are a marker or mediator for coronary heart disease and hypertension (e.g., Barnett, Marshall, \& Sayer, 1997; Manuck, Cohen, \& Kaplan, 1994; Marsland et al., 
1995; Mays, Cochran, \& Barnes, 2007). Evidence also suggests that repeated exposure to discrimination may work in ways that prepare the body to be more physically reactive in stressful or potentially stressful social situations (Guyll, Matthews, \& Bromberger, 2001). Similarly, Gee, Spencer, Chen, and Takeuchi (2007) have proposed that routine discrimination can become a chronic stressor that may erode an individual's protective resources and increase vulnerability to physical illness. As with other forms of cumulative stress, perceived discrimination may lead to wear and tear on the body because chronic over- or underactivity of allostatic systems produce allostatic load (e.g., Seeman, Singer, Rowe, Horwitz, \& McEwen, 1997).

In addition to triggering sustained activation of stress responses, discrimination experiences may affect health by decreasing an individual's self-control resources, potentially increasing participation in unhealthy behaviors or decreasing participation in healthy behaviors. For example, research has shown that individuals whose stigma was made salient, thus highlighting the potential for discrimination, had more impaired self-control than those whose stigma was not made salient (Inzlicht, McKay, \& Aronson, 2006). The implication, when applied to the health domain, is that dealing with experiences of discrimination may leave individuals with less energy or resources for making healthy behavior choices. Research examining these pathways suggests that perceived discrimination is related to health behaviors that have clear links to disease outcomes, such as smoking (Landrine \& Klonoff, 1996), alcohol and substance abuse (Bennett, Wolin, Robinson, Fowler, \& Edwards, 2005; Martin, Tuch, \& Roman, 2003; Yen, Ragland, Grenier, \& Fisher, 1999), as well as nonparticipation in behaviors that promote good health, such as cancer screening, diabetes management, and condom use (McSwan, 2000; Ryan, Gee, \& Griffith, 2007; Yoshikawa, Wilson, Chae, \& Cheng, 2004).

Despite the large number of studies examining the relationship between discrimination and health, several questions have remained unanswered. The negative impact of discrimination on mental health outcomes is widely supported, but the evidence is not as clear for the relationship between discrimination and physical health. The main purpose of our meta-analysis was to determine the strength of these relationships and, when possible, to test pathways by which perceived discrimination may affect health. Furthermore, distinctions have been made between the predictive utility of measuring perceived discrimination by self-reported lifetime history of discrimination or reports of the past 12 months and whether major events are more influential on health than more chronic, everyday experiences. These issues were addressed through the use of meta-analysis on the available literature and supplemented by research synthesis for the literature that did not qualify for the meta-analysis. We also explored several potential moderator effects.

\section{Modeling the Perceived Discrimination-Health Relationship}

The model shown in Figure 1 illustrates three pathways through which discriminatory experiences may affect mental and physical health. First, perceptions of discrimination could have a direct effect on health (Path a). The relationship between perceived discrimination and mental and physical health can also be partially mediated through stress responses to a discriminatory event, such as the psychological responses of decreased positive emotion and increased negative emotion (Path $b$ ). If an individual perceives discrimination on a regular basis, these stress responses should be activated more often, potentially leading to a consistently negative emotional state. Chronic, heightened physiological stress responses, such as cardiovascular reactivity and cortisol responses, are also included in this pathway. Experiences of discrimination may contribute to health problems then via Path $\mathrm{c}$ through allostatic load developed by heightened stress responses and negative emotional states. Another mediating mechanism we tested in our model is the role of health risk behaviors (Path d) that may emerge

a

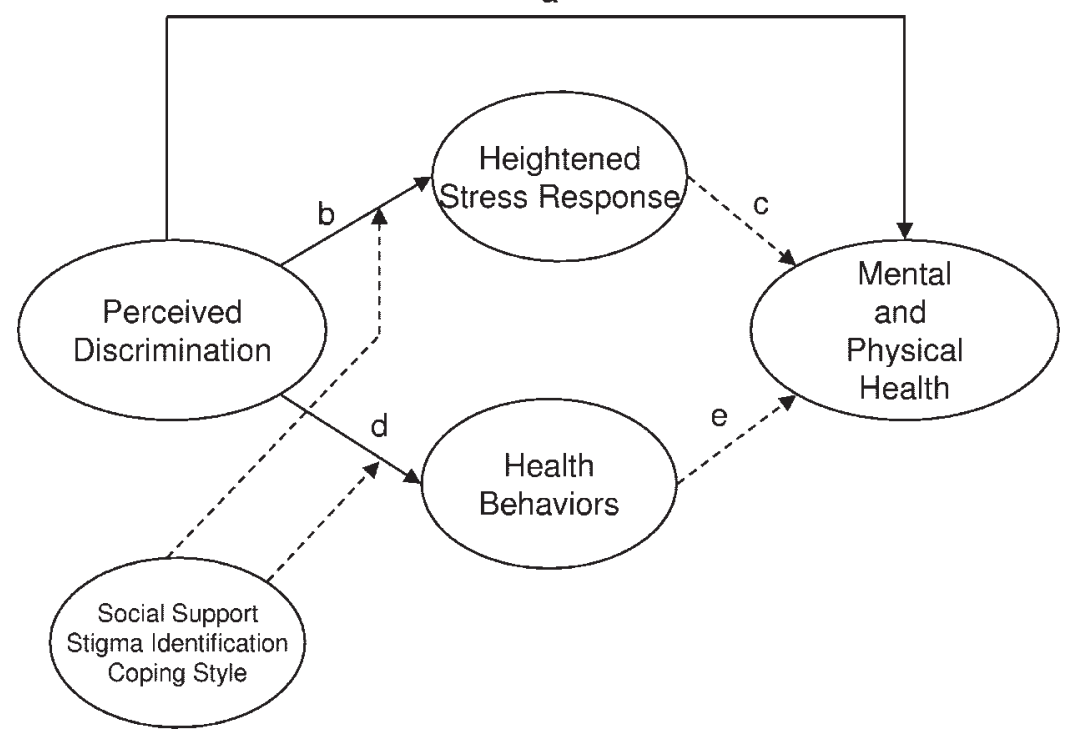

Figure 1. Pathways by which perceived discrimination influences health outcomes. Solid lines indicate analyzed pathways; dashed lines represent pathways hypothesized by past research. 
as possible coping mechanisms when discrimination is experienced. As represented by Path e, these activities can have detrimental effects on physical health, contributing to increased risk of multiple major disease outcomes. We also examined several variables that have been identified in the literature as potential moderators of these pathways.

The meaning and measurement of perceived discriminationdefined as a behavioral manifestation of a negative attitude, judgment, or unfair treatment toward members of a group (Banks, Kohn-Wood, \& Spencer, 2006; D. R. Williams, Spencer, \& Jackson, 1999) - is the subject of some debate regarding the accuracy of discrimination as a construct, because it is perceived and reported by subjects without verification of actual events. In the absence of methods of verification, it is important to note that much of the current work in this area involves perceptions of discriminatory treatment based on self-report of life events and not objectively observed discrimination. We make the assertion in this meta-analysis (as have many other researchers in this area; e.g., D. R. Williams et al., 2003; D. R. Williams, Yu, Jackson, \& Anderson, 1997) that regardless of verification, these experiences can be characterized as a form of stress. Further, as with other stressful life events, measures of acute discriminatory experiences are not representative of an underlying construct and therefore cannot be psychometrically validated via tests of internal reliability. Rather, stressful life events are typically independent of one another and may result in either over- or underestimates of discrimination, as accurate estimates depend on unobservable information such as intent (D. R. Williams et al., 2003). When possible, we consider a range of different forms of discrimination in our analyses.

\section{Moderators of the Perceived Discrimination-Health Relationship}

Past research has revealed several variables that may moderate the link between perceived discrimination and health. These moderators include social support, coping style, ethnic identity, and personality variables. For example, having people to turn to in time of ill health may mean that individuals have access to more health resources such as proper food, health care, and medicine (Heckman, Kochman, \& Sikkema, 2002). In addition, the availability of friends or family to talk to after experiences of discrimination may help to rebuild an individual's feelings of self-worth, potentially preventing depressive symptoms from developing. In one study, gay Latino men who had discussions about discrimination experiences with family and friends were less likely to have unprotected anal intercourse than those who had infrequent conversations with family and friends (Yoshikawa et al., 2004). Noh and Kaspar (2003) found that individuals who sought social support following discriminatory experiences had lower levels of depressive symptoms (see also Smart Richman, Pek, Malone, Siegler, \& Williams, 2008).

The health consequences of perceived discrimination may also vary according to personal coping style. Certain coping strategies may be particularly effective in forestalling the negative consequences of perceived discrimination upon health (Bianchi, Zea, Poppen, Reisen, \& Echeverry, 2004). Although there is scant research on this topic, some work suggests that active coping strategies, such as confrontation, positive reappraisal, and seeking social support, may buffer the effect of discrimination distress by enabling an individual to challenge the validity of discriminatory events and reduce negative feelings about the self, thereby reducing the chance that discriminatory experiences will exert an enduring impact on mental health outcomes. Active coping has also been associated with participation in good health habits (Bianchi et al., 2004), whereas some emotion-focused strategies, often achieved through eating, or the use of alcohol and drugs, can be effective in blocking out the immediate negative mood effects of perceived discrimination. However, frequent participation in this behavior may exacerbate or give rise to other negative health problems, such as obesity (and subsequently diabetes or heart disease) and alcohol and drug dependency (Yen et al., 1999). The coping style most effective in reducing the negative health effects of perceived discrimination is still under debate. Studies done on Southeast Asians in the United States have found that forbearance (emotion-focused coping) diminishes the strength of the link between perceived discrimination and depression (Noh, Beiser, Kaspar, Hou, \& Rummens, 1999), although the efficacy of emotionfocused coping for Asians may be lessened when individuals are more adapted to the Western environment (Noh \& Kaspar, 2003), where active coping seems to be the better strategy.

Having a strong connection to a certain group identity, such as one's ethnic or gender group, may buffer the stress of discrimination by preventing negative stereotypes from infecting the selfconcept. For example, Mossakowski (2003) found that higher levels of racial or ethnic identification were associated with lower levels of depression, regardless of the source of discrimination. However, as with coping style, not all research has found the stress-buffering effect of identity. For example, Noh et al. (1999) found that the interaction between ethnic identification and perceived discrimination augmented the link between perceived discrimination and depression. Although higher levels of stigmatized identity may be capable of buffering the effect of discriminatory experiences by making negative stereotypes less likely to be incorporated into one's self-concept, these high levels of identity might also lead to a higher vigilance regarding discriminatory experiences, potentially increasing the number of times discrimination is perceived.

\section{Current Research}

This research focuses on the direct link between perceived discrimination and health, as well as the pathways between perceived discrimination and health behaviors and perceived discrimination and physiological and psychological stress responses through a combination of meta-analysis and research synthesis. We tested the hypotheses that perceived discrimination does indeed have a significant relationship with (a) both mental and physical health outcomes, (b) causal pathways for heightened psychological and physiological stress responses, and (c) increased participation in unhealthy behaviors and decreased participation in healthy behaviors.

Meta-analysis allows for the calculation of the magnitude of the overall relationship between perceived discrimination and health. Because meta-analysis cannot take into account the potentially confounding covariates of gender, race, socioeconomic status, and age, we did a research synthesis in which the results of studies that control for these covariates were tallied to assess their effect upon 
the perceived discrimination-health relationship, so that the strength of the relationship between perceived discrimination and health when controlling for these variables could be assessed. We also used research synthesis to examine the influence of moderators such as social support, coping style, and group identification.

In addition to examining the pathways represented in Figure 1, we examined the nature of the discrimination measured. Discrimination can be measured in terms of how often it occurs in daily life (chronic); the number of specific, severe experiences of discrimination (acute); whether it has occurred recently (recent); or how much discrimination one has experienced over one's lifetime (lifetime). Through meta-analytic techniques, we examined whether these different ways of measuring perceived discrimination are related to differences in the perceived discriminationhealth relationship.

\section{Benefits and Limitations of Data Presentation and Meta- Analysis for This Topic}

There are several reasons why a synthesis of this literature is needed. A meta-analytic review of the perceived discriminationhealth literature could help quantify the actual size of the relationship between perceived discrimination and health as well as test the strength of our proposed pathways. In addition, existing reviews have left some questions unanswered, taking into account portions of the perceived discrimination-health literature by using data from only published sources. Although there are many reasons why researchers may limit their reviews to a subset of the literature, a complete research synthesis takes into account all available literature, to help account for publication bias toward significant results. The use of a meta-analytic approach can also account for the sample size of each study, with studies being weighted by their sample size as part of their inclusion into the analysis, helping to overcome a major limitation of standard research synthesis methods.

However, because the outcomes of interest can be measured in a variety of ways and analyzed with different types of models, the discrimination literature reflects this variation. For example, some researchers may test effects with mean differences, others may report correlation matrices, and others may report relationships through the use of odds ratios. This variation can make the metaanalytic comparison of data a challenge.

To compare data reported in different formats meaningfully, meta-analysts must convert one piece of data to the other's metric. Meta-analysts and statisticians propose that one can convert an odds ratio into a Digby (1983) correlation transformation. Similarly, standardized betas from regression analyses are comparable to correlation coefficients when nothing else is controlled for in the regression model. Standardized mean differences may also be transformed into correlation coefficients with the proper formula (see J. Cohen, 1988). Within this analysis, we converted standardized mean differences, odds ratios, and beta weights into correlations coefficients when appropriate to allow for the most comprehensive analysis of available data. We chose the correlation coefficient for the unit of analysis because correlation coefficients are more frequently reported within this literature than standardized mean differences and odds ratios.

Even though these metrics may be comparable in some circumstances, there are situations in which it is not appropriate to compare correlations to beta weights and odds ratios. When other variables are controlled for within the analysis model, transformation cannot be achieved unless all models control for the same variables. This is a particular problem in health research, as many preexisting variables may be influencing the perceived discrimination-health pathway, exaggerating the effect or masking the effect when left uncontrolled. To properly compare the perceived discrimination-health link, all studies would need to control systematically for the same variables. For example, a partial correlation table or an initial regression analysis with a standardized set of variables such as age, socioeconomic status, race, and gender included in every article would allow for these same variables to be used as covariates within a meta-analysis.

Because control variables used in the literature have been inconsistent, results from any current meta-analysis on perceived discrimination and health are limited to zero-order associations. As a supplement to zero-order correlations, the data from models controlling for important variables (such as those mentioned above) were tallied according to the methods employed by previous review articles. Although this is not the ideal method of comparison when trying to illuminate the exact magnitude of the perceived discrimination-health relationship, vote counting allows for these studies to be represented within this review.

\section{Methods for Research Synthesis}

\section{Literature Search Procedures}

The literature search procedure for this analysis was designed to locate both published and unpublished research. The primary method of retrieval was through major electronic databases, including PsycINFO, Sociological Abstracts, and MEDLINE. Because there has not been a major quantitative analysis encompassing all aspects of perceived discrimination and health in the field, publication date was not restricted. Discrimination-related keywords used in database searching included discrimination, prejudice, racism, sexism, and unfair treatment. Each of these keywords was included with each of the following health keywords in turn: health, cardio*, blood pressure, smok ${ }^{*}$, alcohol ${ }^{*}$, depress ${ }^{*}$, anxiety, self-esteem, life satisfaction, psychological distress, well being, anger, mental, psychological stress, and perceived stress. The computer database search located approximately 769 articles, dissertations, and book chapters. If the titles and abstracts of the above documents indicated the article might contain data relevant to this analysis (see Criteria for Including Studies below), the full document was retrieved. This process ultimately identified approximately 192 studies relevant for further study, which spanned 1986-2007.

In addition, we mined the citations of several articles highly relevant to the analysis topic, including the review articles described above, for important articles the database search may have missed. This method of retrieval revealed 18 potentially relevant articles. Finally, to locate articles that may be unpublished or in press and therefore undetectable by the previous methods, we sent a call for unpublished and in-press papers to the Society for Personality and Social Psychology e-mail listserv. The Society for Personality and Social Psychology is a professional association with over 4,500 members that represents the largest organization of social and personality psychologists in the world. The listserv 
request was informally passed on by society recipients to researchers in behavioral medicine, health psychology, and public health who may not have received the original request and who also sent material to us. A number of prominent researchers outside social psychology were also contacted directly by Laura Smart Richman. A total of 18 manuscripts, posters, and papers in progress or under review were received and were eligible for inclusion in the analysis.

\section{Criteria for Including Studies}

To be included in the research synthesis, an article needed to meet a variety of criteria. Most important, the article had to contain data relating discrimination to a health outcome. Specifically, because the focus of this analysis was the relationship between the actual perception of discrimination and health outcomes, articles needed to contain a measure of discrimination or an unfair treatment score based on the individual's perception of being discriminated against. Studies that examined group differences in health outcomes without measuring perceived level of discrimination, such as a comparison study of cardiovascular disease rates for Blacks and Whites, were excluded from the analysis. This exclusion extended to studies in which the main determinant of discrimination was assessed by the researcher and not the participant, such as reports of pollution levels, percentage of a certain ethnic group living in segregated area, and differential clinical diagnoses (mental and/or physical) based solely on race or gender of the respondents.

Statistical criteria for inclusion were that each article needed to report sufficient data for us to calculate a correlation coefficient. Correlation coefficients were found in the literature in one of four ways. First, authors could provide an actual correlation coefficient in the article. Authors could also provide standardized betas in a univariate regression model, which are equal to correlation coefficients in this form. Third, authors could provide unadjusted odds ratios that could be converted to a correlation coefficient with the formula suggested by Digby (1983): $\left(\mathrm{OR}^{3 / 4}-1\right) /\left(\mathrm{OR}^{3 / 4}+1\right)$, where $\mathrm{OR}=$ odds ratio. Finally, authors could provide sufficient data for us to calculate standardized mean differences, which we could convert to correlation coefficients using the Comprehensive Meta-Analysis software (Borenstein, Hedges, Higgins, \& Rothstein, 2005). For us to calculate a standardized mean difference, articles needed to provide the following: means, standard deviations, and sample sizes for both high-discrimination and lowdiscrimination groups; means for each group, along with a total sample size and paired-groups $t$ value; means and sample sizes for the high-discrimination and low-discrimination groups, along with an independent-groups $t$ value; or the standardized mean difference itself, along with the lower limit, upper limit, confidence level, and effect direction. All effects used within the metaanalytic portion of this review are zero-order.

Articles that met all other criteria but did not provide sufficient data for us to calculate a zero-order correlation coefficient were included in the review portion of this research only. A total of 78 articles did not contain appropriate data or did not present sufficient data for meta-analysis.

\section{Coder Reliability}

Two coders extracted the above information from each report selected for inclusion. Any discrepancies were noted and checked against the original articles. Because all studies were independently coded twice and all discrepancies were able to be resolved through consultation of the original document, we did not calculate a reliability statistic for this process (see Cooper, Civey Robinson, \& Patall, 2006).

\section{Methods of Data Integration}

\section{Identifying Independent Hypothesis Tests}

When several associations are measured within the same sample, the effect sizes are not independent. To avoid problems regarding independence of associations, we used a shifting unitof-analysis approach (Cooper, 1998). Each association within a study was first coded as if it were an independent estimate of the relationship between perceived discrimination and health. For example, if a single sample produced comparisons between perceived discrimination and both depression and anxiety, we calculated two correlations: one representing the relationship between perceived discrimination and depression and the other between perceived discrimination and anxiety. When estimating the overall effect of perceived discrimination on health, we averaged these two correlations so that the sample contributed only one overall association to the analysis. However, when analyzing the relationship between perceived discrimination and depression and anxiety separately, this sample could contribute an association for the estimate of each health category's mean correlation. This process allowed for the retention of as much data as possible from each study, while maintaining any violations of independence to a minimum. Similarly, multiple associations within multiply-used data sets, such as the Family and Community Health Study (Brody et al., 2006; Murry, Brown, Brody, Cutrona, \& Simons, 2001; Simons, Chen, Stewart, \& Brody, 2003; Simons et al., 2002, 2006), were averaged when calculating average correlations, so that each multiply-used data set contributed only one association to the overall analysis. Additionally, we weighted effect sizes for sample size using the Comprehensive Meta-Analysis software, so that effects from bigger samples were given more influence on the combined results. This weighting addressed methodological questions over small sample sizes from earlier reviews. Nonexperimental studies were examined separately from experimental studies.

Although meta-analysis does allow for the computation of an overall association between perceived discrimination and health, multivariate relationships still present a significant challenge for meta-analysis (see Lipsey \& Wilson, 2001). Independent variables in these models differ from study to study, thus presenting complications for estimating effect sizes comparable between these studies. Because these associations were generally not presented within a multivariate framework, we performed our analysis of moderator influences using standard research synthesis procedures.

\section{Fixed and Random Error}

Both fixed and random models of error were applied in this research. We conducted each analysis twice, once under a fixed- 
effects model and once under a random-effects model. Employing this method enabled us to suggest any limits of generalizability of analyses. An effect that appears significant within a fixed-effects model but not within a random-effects model would suggest there is a limit to the generalizability of that particular relationship. However, we present only random-effects model results because variation in methodology and measures used, as well as populations sampled by the studies included in this analysis, suggests that error will not solely stem from participant differences.

\section{Sample Retrieval Bias}

We used several techniques to evaluate whether the studies used in this analysis were biased toward the inclusion of associations that are more likely to be statistically significant: those with large effect sizes and those from large samples. First, we examined funnel plots of associations. Funnel plots show associations as a function of the precision of the effect size estimate (one standard error), and data without bias will form a plot that is symmetrical in the funnel pattern. Data showing bias for statistically significant effects will form a plot that is asymmetrical in the funnel. To account for potentially omitted values based on the funnel plot, we used Duval and Tweedie's (2000a, 2000b) trim-and-fill method. Trim-and-fill estimates calculate effect size under the assumption that the values omitted on the funnel plot can be located and included. This procedure imputes the missing values on the funnel plot to make it symmetrical. Finally, to test directly for publication bias in the sample of studies, we compared the mean effect size from published sources (journal articles, book chapters) with that of unpublished sources (dissertations, unpublished manuscripts, posters, and conference presentations).

\section{Results}

A total of 192 articles were identified as containing data relating perceived discrimination to a health outcome (see Table 1). A subset of 134 of these 192 articles contained the appropriate data for inclusion in the meta-analysis. The majority of the articles were published: $90 \%$ of the overall sample and $90 \%$ of the metaanalysis subsample. These articles were published between 1986 and 2007, with an average publication year of 2002-2003.

Ninety-one percent of articles in the total sample and $91 \%$ of the meta-analysis sample articles measured perceived discrimination through a survey self-report of perceptions of discrimination occurring in the past. The most common type of perceived discrimination measured was racial or ethnic discrimination, found in $65 \%$ of the articles in the total sample and $66 \%$ of the articles in the meta-analysis subsample. The most frequently used racial discrimination questionnaires included the Perceived Racism Scale (10\% of both samples measuring racial discrimination), the Schedule of Racist Events (11\% of meta-analysis sample, $9 \%$ of overall sample), the Index of Race Related Stress (7\% of both samples), and the Racism and Life Experiences Scale (5\% of meta-analysis sample, $5 \%$ of total sample).

Seventeen percent of the meta-analytic sample and $14 \%$ of the total sample investigated gender discrimination. For gender discrimination, the Schedule of Sexist Events was most popular scale (23\% of meta-analysis sample measuring gender discrimination and $21 \%$ of total sample measuring gender discrimination). Six
Table 1

Sample Description

\begin{tabular}{lcc}
\hline \multicolumn{1}{c}{$\begin{array}{c}\text { Sample } \\
\text { characteristic }\end{array}$} & Total sample & Sample for analysis \\
\hline $\begin{array}{l}\text { Number of articles } \\
\text { Sample size }\end{array}$ & 192 & 134 \\
$M$ & & \\
Range & 638 & 530 \\
Female (\%) & $30-8,311$ & $30-8,311$ \\
Publication & $58 \%$ & $57 \%$ \\
Published & 173 & 121 \\
Unpublished & 19 & 13 \\
Year published & & \\
$M$ & 2003 & 2003 \\
Range & $1986-2007$ & $1987-2007$ \\
Study design & 15 & 10 \\
Experimental & 177 & 124 \\
Nonexperimental & & \\
Discrimination type & 125 & 88 \\
Racial & 29 & 22 \\
Gender & 13 & 8 \\
Sexual orientation & 21 & 6 \\
Unfair treatment & 10 & 7 \\
Other & 10 & 110 \\
Not specified & & 40 \\
Health reported & 161 & 14 \\
Mental health & 70 & 15 \\
Physical health & 21 & \\
Stress response & 26 & \\
Health behavior & & \\
\hline & & \\
\hline
\end{tabular}

Note. Totals sum to an amount larger than the total number of articles because of some studies presenting multiple types of metric, discrimination, and health outcome.

percent of the meta-analysis sample and total sample looked at discrimination based on sexual orientation. An adaptation of the Schedule of Racist Events modified for measurement of discrimination based on sexual orientation was the most frequently used scale to measure this type of perceived discrimination $(40 \%$ of meta-analysis sample looking at sexual orientation, $31 \%$ of total sample measuring sexual orientation).

Fifteen percent of studies in the meta-analysis sample and $15 \%$ of the total sample measured unfair treatment or did not specify discrimination type. The most frequent unfair treatment scale was D. R. Williams et al.'s (1997) scale (26\% of meta-analysis sample not specifying discrimination type, $53 \%$ of total sample not specifying discrimination type). Across all types of discrimination, studies generally contained scales or questions regarding perception of discrimination within a variety of domains, such as poor service and treatment in public situations, derogatory comments, and harassment.

\section{The Direct Perceived Discrimination-Health Pathway}

Figure 1 shows the hypothesized direct link between perceived discrimination and health (Path a). This pathway was examined through the meta-analysis of nonexperimental study results.

\section{Mental Health}

One hundred ten studies presented sufficient data on the zeroorder relationship between perceived discrimination and mental 
health to be included in the meta-analysis on the effect of perceived discrimination on mental health. These mental health outcomes included symptomatology scales for mental illness (e.g., depressive symptoms, anxiety symptoms, posttraumatic stress symptoms, and indicators of psychosis or paranoia), psychological distress, and indicators of general well-being (e.g., well-being, self-esteem, positive self-perceptions, life satisfaction, perceived stress, anger, positive and negative affect, happiness, perceived quality of life, and general mental health).

Of those studies that simultaneously used data from nationally available data sets, two used data from the National Survey of Black Americans (J. S. Jackson et al., 1996; P. B. Jackson \& Mustillo, 2001), three used data from the Study of Women's Health Across the Nation (C. Brown, Matthews, Bromberger, \& Chang, 2006; Lewis et al., 2006; Troxel, Matthews, Bromberger, \& Sutton-Tyrrell, 2003), five used data from the Family and Community Health Study (Brody et al., 2006; Murry et al., 2001; Simons et al., 2002, 2003, 2006), three used data from the Midlife in the United States data set (Bierman, 2006; Kessler, Mickelson, \& Williams, 1999; Rodriquez, 2004), two used data from the Developing Theory and Methodology in the Study of the Effects of Discrimination and Marginalization data set (Jasinskaja-Lahti \& Liebkind, 2007; Jasinskaja-Lahti, Liebkind, \& Perhoniemi, 2007), one used data from the New Zealand Health Survey (Harris et al., 2006), and one used data from the Multicenter AIDS Cohort Study (Frable, Wortman, \& Joseph, 1997). The remaining studies did not use national data sets. Altogether, these 110 studies produced 497 relationships between perceived discrimination and mental health. When a study reported more than one relationship, we averaged all relationships within that study to create an overall effect between perceived discrimination and mental health for that study. In the case of multiple studies using the same national data set (such as the Family and Community Health Study), we listed all studies using that data set as one study, and we averaged relationships from all studies using that data set into one overall effect for the data set. This procedure resulted in a total of 105 effects for analysis.

After being weighted for sample size, the average correlation under a random effect model was -.20 , with a $95 \%$ confidence interval (CI) from -.22 to -.17 . These results support the hypothesized Path a in Figure 1. Increases in perceived discrimination were significantly related to more negative mental health outcomes.

We assessed the existence and extent of bias in effects using several methods. Examination of a funnel plot suggested that the retrieved data tended to have smaller standard errors but were representative of not only effects in the expected direction but also opposite and null effects. Egger's regression intercept (Egger, Davey Smith, Schneider, \& Minder, 1997) for this sample was not significant, statistically confirming the conclusion that publication bias was not present, $t(102)=1.12, p<.26,95 \% \mathrm{CI}=-0.86$, 3.12. Trim-and-fill procedures, searching for missing studies on the right side of the distribution, which, if added, would reduce the size of the negative effect, suggested that 17 studies were missing from the analysis under a random-effects model. Imputing these missing values adjusted the random-effects point estimate from $r=-.20$ to $r=-.16$, with a $95 \%$ CI from -.20 to -.12 (see Table 2). Even with the imputed values, the weighted effects under both models were changed only slightly and remained significantly different from zero. ${ }^{1}$

Further analyses investigated whether perceived discrimination might uniquely affect certain types of mental health outcomes. Given the data available, specific mental health outcomes examined included depressive symptoms $(k=9)$, psychiatric distress $(k=11)$, and a composite variable of general well-being $(k=33)$. Perceived discrimination was found to be negatively related to each mental health outcome. However, no significant differences in average correlation were found between mental health groupings.

Overall, these results suggest that experience with perceived discrimination is related to poorer mental health status. In addition, this relationship does not seem to be specific to certain types of mental health outcomes but instead appears to be equally strong across many types of mental health. However, these analyses are limited by their inability to include covariates that might alter the relationship between perceived discrimination and health. To account for this, we examined studies involving regression analyses, path models, and structural equation models whose models included any covariates for their direction and significance. One hundred seven studies explored the relationship between perceived discrimination and mental health using regression equations, path models, or structural equation models, producing a total of 500 effects. Of these, 448 (90\%) found that higher levels of perceived discrimination were related to more negative mental health status, with $345(69 \%)$ of the 500 analyses reaching significance. Only 34 $(7 \%)$ of the effects showed that increased perceptions of discrimination were related to less negative mental health, with $7(1 \%)$ reaching significance. For 20 (4\%) of the relationships, direction could not be determined.

Diagnosis of mental illness. We also attempted to address whether perceived discrimination was related not just to mental illness symptomatology, distress, or general measures of wellbeing but also to actual diagnoses of mental illness. Because only two studies out of seven that measured actual diagnoses presented sufficient data for meta-analyses, we could not examine this relationship quantitatively (T. Brown et al., 2000; Gee, Spencer, Chen, Yip, \& Takeuchi, 2007; Karlsen \& Nazroo, 2002; Kessler et al., 1999; Loo et al., 2001; Mays \& Cochran, 2001; Seifert, Bowman, Heflin, Danziger, \& Williams, 2000). However, the results from these studies suggest that perceived discrimination is related to an increased probability of manifesting clinical levels of mental illness. Furthermore, these studies suggest that this relationship may be curvilinear and/or additive by strengthening as perceptions of discrimination increase (Gee, Spencer, Chen, Yip, \& Takeuchi,

\footnotetext{
${ }^{1}$ To test whether relationships reported in published material differed significantly from relationships in unpublished material, we ran a moderator analysis of publication status. Of the 110 samples relating discrimination to mental health, 102 were published, whereas 8 remained unpublished. Under a random-effects analysis, published articles showed an overall effect size of $r=-.20$, with a $95 \%$ CI from -.24 to -.16 . Unpublished articles showed a slightly, but not significantly, larger overall correlation of -.17 , with a $95 \%$ CI from -.25 to $-.08, Q(1)=0.47, p=$ .50 . The absolute difference between the relationships was quite small, and correlations from both published and unpublished articles under both models still allow the rejection of the null hypothesis.
} 
Table 2

Meta-Analytic Average Correlations for Perceived Discrimination and Health Outcomes

\begin{tabular}{lrccrrrr}
\hline \multicolumn{1}{c}{ Health outcome } & \multicolumn{1}{c}{$k$} & Mean $r$ & Lower & Upper & $Z$ value & $\begin{array}{r}\text { Heterogeneity } \\
\text { within }\left(Q_{w}\right)\end{array}$ & $p$ \\
\hline Mental health $^{\mathrm{a}}$ & 105 & -.16 & -.20 & -.12 & -11.97 & 7480.44 & $<.00$ \\
Physical health & 36 & -.13 & -.16 & -.10 & -8.13 & 624.26 & $<.00$ \\
Stress response $^{\mathrm{a}}$ & 12 & -.11 & -.18 & -.05 & -3.22 & 87.82 & $<.00$ \\
Health behaviors $^{\mathrm{a}}$ & 13 & -.18 & -.21 & -.15 & -11.07 & 33.24 & $<.00$ \\
\hline
\end{tabular}

Note. Coefficients represent random-effects models.

${ }^{a}$ Represents coefficients adjusted for bias with the trim-and-fill procedure.

2007) or as effects of lifetime discrimination and day-to-day discrimination are compounded (Kessler et al., 1999).

Moderating effect of ethnicity and gender. A random-effects model including Asian, Black, Hispanic, Native American, and White ethnic groups showed no significant differences because of ethnicity, $Q(4)=2.55, p=.64, k=60$. Analyses investigating differences in the effect sizes of perceived discrimination on mental health for male participants compared with female participants also revealed no significant differences, $Q(1)=0.57, p=$ $.45, k=37$. Higher levels of perceived discrimination were related to poorer levels of mental health among all ethnicities and both genders.

\section{Physical Health}

Thirty-six studies reported sufficient data to be included in a meta-analytic examination of the zero-order relationship between perceived discrimination and physical health. A wide variety of physical health outcomes were assessed in these studies, including risk factors related to cardiovascular disease (e.g., blood pressure, intramedial thickness, plaque, and heart rate variability), a multitude of diseases and physical conditions (e.g., hypertension, cardiovascular disease, pelvic inflammatory disease, diabetes, yeast infections, and respiratory conditions), other general indicators of illness (e.g., nausea, pain, and headaches), and general health questionnaires.

Of those studies that used nationally available data sets, one used Coronary Artery Risk Development in Adults data (Borrell, Kiefe, Williams, Diez-Roux, \& Gordon-Larsen, 2006), one used data from the Developing Theory and Methodology in the Study of the Effects of Discrimination and Marginalization (JasinskajaLahti et al., 2007), one used data from the Health and Growth of Puerto Rican Children study (Szalacha, Coll, Alarcón, Fields, \& Ceder, 2003), one used data from the National Survey of Black Americans (J. S. Jackson et al., 1996), one used data from the New Hampshire Racial and Ethnic Approaches to Community Health 2010 Initiative (Ryan, Gee, \& Laflamme, 2006), one used data from the Reactivity and Cardiovascular Risk Trial (H. S. Thompson, 1999), one used data from the National Institute of Environmental Health Sciences Uterine Fibroid Study (Vines et al., 2007), and one used data from the New Zealand Health Survey (Harris et al., 2006). Because no study shared use of the same national data set, 36 studies were used as the unit of analyses. These 36 studies produced 303 individual relationships between perceived discrimination and physical health. After multiple health effects were combined within single studies, a total of 36 effects were available for meta-analytic examination.

After we weighted for sample size, the average relationship under a random-effects model was $r=-.13$, with a 95\% CI from -.16 to -.10 . This result supported the hypothesis that increased levels of perceived discrimination are related to poorer physical health (see Table 2). Examination of a funnel plot suggested that the observed studies tended to have relatively small standard errors and were representative of both negative and positive effects. This conclusion was confirmed by Egger's regression intercept, which was not significant, $t(34)=1.91, p<.06,95 \% \mathrm{CI}=-0.09,2.97$. $^{2}$ Trim-and-fill analyses indicated no missing studies.

Similar to the mental health analyses, regression analyses, path models, and structural equation models examining the perceived discrimination-physical health relationship that included any type of covariate were studied to supplement the meta-analytic results. ${ }^{3}$ Forty-three studies examined the relationship between perceived discrimination and physical health, resulting in a total of 222 regressions, path models, or structural equation models. Eightythree percent (184 analyses) showed that higher levels of perceived discrimination were related to negative physical health outcomes, although only $42 \%$ (93 analyses) reached significance in this direction. Fifteen percent of the studies (33 analyses) found that increases in perceived discrimination were related to less negative health outcomes, although only $1 \%$ were significant in this direction ( 2 analyses). These reverse effects were the result of interactions with other variables, such as coping style and social support.

\footnotetext{
${ }^{2}$ Further analysis of the effect of publication bias on effect size for physical health was performed in the same way as described above for mental health. Of the 36 studies used in the meta-analysis, 33 were published and 3 were unpublished. Under a random-effects model, the average weighted correlation for published studies was -.14 , with a $95 \%$ CI from -.17 to -.11 . For unpublished studies, the average weighted correlation was -.06 , with a $95 \% \mathrm{CI}$ from -.13 to $.02, Q(1)=4.09, p=$ .04 . Because the absolute difference between published and unpublished correlations was more substantial than for mental health, and the average correlation for unpublished articles did not reach significance under a random-effects model, there is evidence that correlations from published articles are likely to be larger than those in unpublished studies.

${ }^{3}$ Investigation of differential effects for specific types of physical health outcome or risk pathway was not performed because of the widely disparate nature of the physical health outcomes (see Table 5 of the supplementary materials for more detailed information of the types of physical health outcomes studied).
} 
For example, Clark and Adams (2004) found that Black women who used active coping saw a protective effect on systolic and diastolic blood pressure, and Clark (2003) found that individuals with high social support networks showed fewer systolic and diastolic blood pressure changes but only when perceived discrimination was low. Directionality could not be determined for $2 \%$ (5) of the analyses.

Moderator analyses for race or ethnicity could not be performed because of low numbers of studies reporting sufficient data for groups other than Blacks $(k=15)$. Separate physical effects for Whites, Hispanics, and Native Americans were reported in only one study for each group. Similar to mental health analyses, moderator analyses investigating differences in the perceived discrimination-physical health effect size between gender groups were not significant, $Q(1)=0.34, p=.56, k=13$.

\section{Mental Versus Physical Health Outcomes}

Some researchers have wondered whether perceptions of discrimination may have a more negative impact on mental or physical health. One can begin to speculate on the answer to this question by examining differences in the zero-order relationship with perceived discrimination both between and within studies for these two types of health outcome. However, caution should be taken in interpreting the following analyses, as they are merely exploratory and not definitive answers to this question.

To examine the differential relationship of perceived discrimination on mental and physical health outcomes, we performed an analysis comparing physical and mental health both between and within studies. The effect of perceived discrimination was not significantly different for mental and physical health between studies under a random-effects model. However, the point estimate trended more negative for mental health $(r=-.20,95 \% \mathrm{CI}=$ $-.24,-.16)$ compared with physical health $(r=-.15,95 \% \mathrm{CI}=$ $-.22,-.07)$. When mental and physical health outcomes were examined within samples, no significant differences were found in the relationship between perceived discrimination and mental health and perceived discrimination and physical health under a random-effects model $(r=.06,95 \% \mathrm{CI}=-.02, .12, k=25)$, where a positive correlation represents a stronger effect for mental health compared with physical health.

\section{Covariate Analyses}

To further address the influence of common covariates upon the pathways of our model, we summarized regression analyses containing demographic variables separately. Very few of the examined studies controlled for the same variables, so the effect of each covariate or specific subsets of covariate groups could not be determined. However, 19 studies controlled for one or more of only the following demographic covariates within 44 regression analyses: age, gender, race, socioeconomic status, education, income, marital status, and employment. Despite the inclusion of some combination of these demographic covariates, 18 of the 19 studies $(95 \%)$ still showed a significant negative relationship between any form of perceived discrimination and mental or physical health outcomes. The remaining study showed that, with the inclusion of these covariates, only chronic and not acute discrimination was related to health outcomes for Blacks and neither type of perceived discrimination was significant for Whites (D. R. Williams et al., 1999). These analyses suggest that the negative relationship between perceived discrimination and health is robust, even when controlling for potential confounding variables.

\section{The Perceived Discrimination-Stress Response Link}

We focused on studies that used experimental methods to manipulate perceptions of discrimination experiences to test the hypothesized link between perceived discrimination and stress responses (see Figure 1, Path b). These experimental methodologies included watching racist film clips, imagining racially noxious scenes, receiving feedback from supposed sexist evaluators, reading articles describing discrimination against the participant's ingroup, speaking about racially charged topics, and writing about past experiences of discrimination. Twelve studies presented sufficient zero-order data to use within the meta-analysis. Of these 12 studies, 2 examined physical stress response in the form of cardiovascular reactivity, whereas the remaining 10 considered psychological stress responses to perceived discrimination. Psychological responses to stress included anger (three studies), reports of psychologically felt stress (three studies), changes in state selfesteem (three studies), changes in feelings of well-being and life satisfaction (one study), feelings of depression and anxiety (one study), and self-reported positive and negative emotion (one study).

Stress responses were coded so that harmful effects of current mental and physical states were in the same direction. These deleterious effects were coded as negative for the analysis. Thus, increases in physical responding such as cardiovascular reactivity were coded in the same direction as decreases in self-esteem and increases in depressive symptomatology, because all three of these effects represent a detrimental effect of perceived discrimination on current physical and mental state. We acknowledge that there are important differences between these stress responses, but given the limited data available, we chose to collapse across these stress responses to do exploratory analyses of the evidence for this pathway.

After we weighted for sample size, the average effect between perceived discrimination and stress response under a randomeffects model was $r=-.11$, with a $95 \% \mathrm{CI}$ from -.18 to -.05 (see Table 2). These results suggest that experiences of perceived discrimination can cause increases in multiple forms of stress response. Examination of the funnel plot suggested that these studies were representative of both positive and negative stress responses. Egger's regression coefficient confirmed little evidence of bias, $t(10)=0.24, p<.46,95 \% \mathrm{CI}=-4.66,3.77$. Trim-andfill procedures did not suggest imputation of studies on either side of zero. ${ }^{4}$

\footnotetext{
${ }^{4}$ Further analyses were performed to investigate publication bias. Of the 12 studies included in the analysis, 8 were published and 4 were unpublished. Under a random-effects model, published studies showed an average effect of $r=-.12$, with a $95 \%$ CI from -.19 to -.05 . Unpublished studies showed an average effect of $r=-.08$, with a $95 \%$ CI from -.29 to $.14, Q(1)=0.12, p<.73$. These results suggest that published studies tend to report more negative effects than unpublished studies, although the $Q$ statistic suggests this difference is not significant.
} 
Twelve of the retrieved experimental studies did not include sufficient data to be included in the meta-analysis, because of either incomplete reporting or the use of regressions that included covariates. Five of these studies looked at physiological stress responses, and six examined psychological stress responses. The five studies examining physiological stress response looked at a variety of cardiovascular indicators, including systolic and diastolic blood pressure changes, mean arterial pressure, and total peripheral resistance. All five studies revealed some sort of significantly increased physiological responding in response to the discrimination manipulation.

The six studies examining psychological stress responses produced 18 relationships. Eighty-nine percent of these relationships found that experiences of discrimination were related to negative psychological responses, and 50\% were significant in this direction. Only one study found experiences of discrimination to cause a less negative psychological response (McCoy \& Major, 2003). In this study, women evaluated by a sexist evaluator tended to report less depressed emotion than women rated by a nonsexist evaluator, highlighting the importance of contextual ambiguity in the discrimination-health relationship. Overall, however, results suggest that perceived discrimination may produce a negative psychological stress response.

Not enough data were available to perform moderator analyses between studies on race or gender.

\section{The Perceived Discrimination-Health Behavior Link}

We analyzed studies measuring the relationship between perceived discrimination and a variety of health behaviors to examine this pathway identified in our model (see Figure 1, Path d). These behaviors included alcohol use and abuse (five studies), smoking behavior (four studies), substance use (three studies), good health habits (e.g., sleep, diet, exercise; three studies), medication adherence (one study), missing doctor appointments (one study), and eating behaviors and attitudes (two studies).

We were not able to determine a causal pathway for this part of the model because none of these studies used experimental methods to manipulate discrimination. However, some researchers have suggested that discriminatory experiences may lead to increased participation in unhealthy behaviors such as smoking and alcohol use as a way of escaping the negative affect and cognition that perceptions of discrimination may evoke (Bennett et al., 2005; Landrine \& Klonoff, 1996; Martin et al., 2003; Yen et al., 1999). Other research has suggested that stigma salience (and thus the increased potential to perceive discrimination) may elicit decreases in self-control (Inzlicht et al., 2006). Impaired self-control as a result of discriminatory experiences may make individuals less able to resist engagement in risky activities such as drug use, alcohol use, and unprotected sex.

Like stress responses, health behaviors were coded so that behaviors related to harmful health effects were in the same direction. For example, decreased participation in positive health habits was coded in the same direction as increased alcohol use and smoking behavior, as all three effects represent potentially detrimental effects of perceived discrimination on health-related behaviors.

Thirteen studies provided sufficient data on the zero-order link between perceived discrimination and health behavior to be in- cluded in the meta-analysis. These 13 studies produced 36 separate relationships, and we averaged relationships within studies to produce 13 overall coefficients for analysis. After we weighted for sample size, the average effect between perceived discrimination and health behavior was $r=-.18$, with a $95 \%$ CI from -.22 to -.15 . These results suggest that increases in perceived discrimination may be related to decreased participation in healthy behavior and/or increased participation in unhealthy behavior.

We examined a funnel plot to detect bias in the sample, which revealed that although effects tended to cluster on the left side of the mean, there was some representation of results in the opposite direction. Egger's regression intercept confirmed that bias was not present, $t(11)=0.43, p<.68,95 \% \mathrm{CI}=-0.96,1.43$. Trim-andfill procedures suggested the imputation of one study to the right of the mean. This imputation adjusted the random-error point estimate from $r=-.183$ to $r=-.179$, with a $95 \%$ CI from -.21 to -.15 . Even with the imputation, the estimate was changed only slightly and remained significant. ${ }^{5}$

Thirteen studies relating perceived discrimination to health behavior lacked sufficient data to be included in the meta-analysis, because of either incomplete reporting or the use of regression analyses with the inclusion of covariates. Within these 13 studies, 64 regressions and structural equation models were examined. Of these 64 relationships, 89\% (57 effects) found perceived discrimination to be negatively related to healthy behaviors, and 72\% (46 effects) were significant in this direction. Five effects showed that perceived discrimination was related to fewer negative health behaviors, although these results were not significant. Directionality could not be determined for two relationships. Overall, these results provided support to the meta-analytic results, suggesting that the perception of discrimination is related to the increased participation in unhealthy behaviors and/or the decreased participation in healthy behaviors.

Analyses investigating race and ethnic differences in the perceived discrimination-health behavior relationship for Blacks and Native Americans were not significant, $Q(3)=0.001, p=.98, k=$ 6. Analyses for Whites, Asians, and Hispanics could not be performed because of either only one study or no study giving separate health behavior information for these ethnic groups. However, moderator analyses of gender found significant differences, although the number of studies involved was small, $Q(1)=7.27$, $p<.01, k=6$. Perceived discrimination was related to significantly poorer participation in healthy behaviors for female participants $(r=-.26,95 \% \mathrm{CI}=-.33,-.20)$ than for male participants $(r=-.14,95 \% \mathrm{CI}=-.20,-.08)$.

\section{Perceived Discrimination Measurement and Health Outcomes}

We also determined whether the type of perceived discrimination had an influence on our outcomes of interest. Specifically, we divided up the literature according to whether the perceived discrimination was measured as lifetime, chronic, or recent on mental

\footnotetext{
${ }^{5}$ All 13 studies examining the link between perceived discrimination and health behavior were published. Therefore, publication bias could not be examined with a moderator analysis as was performed for the other health outcomes.
} 
health, physical health, and health behaviors. Not enough data were available to examine the effects of acute discrimination experiences on health in a meta-analytic fashion.

\section{Mental Health}

The comparison of lifetime, recent, and chronic discrimination revealed a significant difference for mental health outcomes, $Q(2)=7.39, p<.05, k=59$. Closer analyses revealed that recent discrimination had a more significant negative effect on mental health than lifetime discrimination $(r=-.25$ and $r=-.15$, respectively). Analyses comparing lifetime $(k=27)$ and chronic discrimination $(k=16)$ were nonsignificant, although the point estimate for chronic discrimination was more negative than that for lifetime discrimination ( $r=-.19$ and $r=-.15$, respectively).

\section{Physical Health}

No significant differences were found in an overall analysis of discrimination type, $Q(2)=0.07, p=.71, k=25$. However, the point estimate for chronic discrimination trended more negative than that for lifetime discrimination, with the point estimate for recent discrimination falling in the middle $(r=-.17, r=-.12$, and $r=-.14$, respectively).

\section{Health Behavior}

Analyses of discrimination type on the perceived discrimination-health behavior relationship were not significant, $Q(2)=3.08, p=.22, k=12$, although chronic discrimination tended to have a more negative effect than lifetime discrimination, with recent discrimination falling in the middle $(r=-.24, r=$ -.13 , and $r=-.22$, respectively). Although they were not consistently significant, these results imply that more recently experienced or more chronically experienced discrimination stress may have the most deleterious effects on health outcomes.

\section{Moderator Analyses of Social Support, Coping Style, and Group Identification}

Because meta-analytic procedures were unable to incorporate these potential moderators of the perceived discrimination-health relationship, we analyzed the effects of social support, coping style, and group identification using research synthesis. To be included in the analysis, studies needed to contain statistics assessing the interactive effect between perceived discrimination and the moderator variable upon a health outcome.

\section{Social Support}

Fifteen studies that examined the interactive effect of social support on the perceived discrimination-health relationship were retrieved. Within these studies, social support was generally defined as an individual's perception of having one person or multiple people available to provide assistance when needed. Most studies focused on either the existence and availability of social support networks (Clark, 2003; Goldenhar, Swanson, Hurrell, Ruder, \& Deddens, 1998; Guttieres, Saenz, \& Green, 1994; McNeilly et al., 1995; Redman \& Snape, 2006; Salgado de Snyder, 1987) or the type or quality of support that individuals are given (Clark, 2003; Finch,
Kolody, \& Vega, 2000; Finch, Catalano, Novaco, \& Vega, 2003; Noh \& Kaspar, 2003; Redman \& Snape, 2006). Two major types of support that were investigated within this realm included instrumental support and emotional support. Instrumental support was generally defined in terms of action, such as giving advice, loaning money, and providing comfort (Finch et al., 2000; Finch, Hummer, Kolody, \& Vega, 2001). Emotional support was thought to revolve more around the sharing of personal thoughts and feelings, as well as the provision of affection, security, and belonging (Finch et al., 2000, 2001). The remainder of studies measured different types of support but used a composite social support measure in analyses (P. W. Barnes, \& Lightsey, 2005; Clark, 2006a; Prelow, Mosher, \& Bowman, 2006; Smart Richman, Pek, et al., 2008; Utsey, Lanier, Williams, Bolden, \& Lee, 2006; Zamboni \& Crawford, 2007). Social support was deemed positive or buffering when it was related to a reduced impact of discrimination on negative health.

Mental health. Within 22 effects, 10 of these 15 studies examined social support with regard to the effect of perceived discrimination upon mental health. Five effects $(23 \%)$ found increased social support to be related to a smaller effect of perceived discrimination on depression (one effect) and general well-being (four effects). Although 17 effects (77\%) revealed null results, social support was not found to be linked to intensified mental distress or negative well-being as a result of discrimination in any study.

Physical health. Six studies investigated the relationship between social support, perceived discrimination, and physical health within 15 effects. Only one study found a beneficial effect of social support for the perceived discrimination-physical health relationship regarding general health problems, and that relationship was qualified by race (Guttieres et al., 1994). Four effects (27\%) within two studies found social support to exacerbate the effects of discrimination upon blood pressure (Clark, 2003, 2006a). Specified social support types found to intensify the perceived discrimination-physical health relationship included ethnic support (one effect), quantity of support (two effects), and quality of support (one effect). The remaining 10 of the total 17 effects (59\%) showed a null effect of social support.

Stress response. Only one study investigated the effect of social support on stress responses to perceived discrimination (McNeilly et al., 1995). In seven effects, this study examined both physiological responses (three effects) and psychological responses (four effects) to racial discrimination with regard to support given by a confederate. Only one negative psychological effect was found to be alleviated by social support. Support had no effect on the remaining six effects.

Health behaviors. Using one effect, one study examined instrumental support's effect on the relationship between racial discrimination and alcohol abuse. In this study, instrumental support was found to buffer this relationship.

Overall, when beneficial effects of social support emerged, they often occurred only under certain conditions. Five analyses found that the buffering effect of social support on the perceived discrimination-health relationship was dependent on the level of perceived discrimination experienced. For example, Clark (2003) found that social support buffered the perceived discriminationhealth relationship only when discrimination stress level was low. Social support did not buffer the relationship when discrimination 
stress was high. Other studies found that social support was protective for some outcomes and not others. Perceptions of high social support have been found to buffer negative mental health outcomes, such as anger intensity (McNeilly et al., 1995), but the relationship with cardiovascular reactivity and physical health indicators was not significant in this same study. Finch et al. (2001) also found that social support was a buffer to the experience of stress and self-rated poor health when people have experienced discrimination, but was unrelated to chronic conditions.

Although patterns were difficult to determine within this analysis, the amount and type of social support given may be important factors to consider when investigating both positive and negative effects of support on the perceived discrimination-health relationship. For example, Finch et al. (2001) found that the buffering effect of social support was apparent for instrumental social support but not for emotional social support. However, Clark (2006b) found that higher levels of perceived discrimination were related to higher blood pressure when social support level was low. High social support had no effect on the perceived discrimination-blood pressure relationship.

Altogether, these results suggest that social support may buffer the perceived discrimination-health relationship, but this does not occur universally. Instead, the benefits of social support may be limited to certain types of social support, may be more likely to occur when levels of discrimination stress are low, when certain conditions are present, and only for some health outcomes. However, most studies within this analysis have not found evidence that social support moderates the discrimination-health relationship.

\section{Coping Behavior}

Nine retrieved studies investigated the interactive effect of coping behavior and discrimination on health. Within these studies, coping behavior was generally defined as the efforts in which one engages to protect oneself from the adverse effects of stress (Smart Richman, Pek, et al., 2008). All nine studies examined the effects of specific types of coping behavior. The most commonly studied types of coping behavior were problem-focused coping, emotionfocused coping, active (or approach) coping, and passive (or avoidance) coping. Problem-focused coping referred to a focus on resolving problems related to the source of the stress, whereas emotion-focused coping referred to a focus on the emotions that were evoked by the negative event (Noh et al., 1999; Noh \& Kaspar, 2003). Similar, but different, constructs were active or approach coping, which referred to active behavior and cognitive attempts to deal with the threat, such as through talking to friends, family, and the insulter (P. W. Barnes \& Lightsey, 2005; Clark \& Adams, 2004; Smart Richman, Pek, et al., 2008; Yoo \& Lee, 2005); and passive or avoidant coping, which referred to avoidance of the problem at hand, such as through self-distraction and substance use (P. W. Barnes \& Lightsey, 2005; Foster, Choma, \& Hitchcock, 2007; Moghaddam, Taylor, Ditto, Jacobs, \& Bianchi, 2002; Smart Richman, Pek, et al., 2008).

Coping behaviors were deemed positive or buffering when they reduced the negative impact of discrimination on health in some way. Exacerbation or intensification of the negative effects of discrimination occurred when coping behavior was related to an increased negative effect of perceived discrimination on health.
Mental health. Seven articles, with a total of 26 effects, examined the relationship between coping behavior, perceived discrimination, and mental health. Significant buffering effects revealed passive coping as a buffer of the perceived discriminationdepression relationship in one instance (Noh et al., 1999), and another effect revealed the benefit of active coping (Noh \& Kaspar, 2003). Four effects (15\%) revealed passive coping behavior to augment the negative relationship between perceived discrimination and mental health outcomes such as anger and depression (Moghaddam et al., 2002; Noh \& Kaspar, 2003), whereas no study found a significant exacerbating effect of active coping style. The majority of effects (21 effects, $81 \%$ of analyses) found no extra influence of coping on the relationship between perceived discrimination and health.

Physical health. In terms of the relationship between perceived discrimination and physical health, two studies examined this link with four total effects. Of these four effects, two (50\%) found that active coping style helped lessen the link between perceived discrimination and blood pressure (Clark \& Adams, 2004), whereas none found active coping to intensify this link. Passive coping was not found to significantly buffer or exacerbate the effect of discrimination on physical health. The remainder of effects (two effects, 50\%) found no effect of coping style on this relationship. Both measured passive coping style.

Stress responses. One article examined the interactive relationship between passive coping style and perceived discrimination on psychological stress responses using 12 effects (Foster et al., 2007). Two effects (17\%) found passive coping to interact with discrimination to augment negative psychological stress responses. The remaining 10 effects $(83 \%)$ were not significant.

Health behaviors. No articles examined coping behavior as a moderator for the perceived discrimination-physical health link.

Although many of these effects are null, the emerging picture across all health outcome types suggests that active or problemfocused coping approaches may tend to be more successful than passive or emotion-focused coping approaches in buffering the effect of perceived discrimination upon health. All three significant effects for active coping found it to interact with discrimination in ways that buffered the negative discrimination-health relationship, whereas only one significant effect measuring passive coping showed this same result. Conversely, passive coping may be more likely to intensify the relationship between perceived discrimination and negative health outcomes. For passive coping, four significant effects revealed this exacerbation, whereas no study showed this same effect for active coping.

However, this relationship is not universal and may vary by culture (Noh \& Kaspar, 2003), as well as function better at low levels of discrimination stress. Coping behaviors may also not be as effective at dealing with discrimination stress when discrimination stress levels are high (Clark \& Adams, 2004; Yoo \& Lee, 2005).

\section{Group Identification}

Fifteen studies were retrieved that examined group identification as a moderator of the perceived discrimination-health relationship. Group identification was defined as the importance or centrality of an individual's racial group, gender, sexual orientation, etc., to one's self-concept, depending on the type of discrim- 
ination being measured within the particular article (McCoy \& Major, 2003). All articles measured some type of identity centrality, with the most commonly used measures being Phinney's (1992) Multigroup Ethnic Identity Measure (Lee, 2003, 2005; Romero \& Roberts, 2003; Yoo \& Lee, 2005) and Sellers, Rowley, Chavous, Shelton, and Smith's (1997) Multidimensional Inventory of Black Identity (Garstka, Schmitt, Branscombe, \& Hummert, 2004; Sellers, Caldwell, Schmeelk-Cone, \& Zimmerman, 2003; Sellers, Copeland-Linder, Martin, \& Lewis, 2006). Other scales used included the Importance to Identity subscale of Luhtanen and Crocker's (1992) Collective Self-Esteem Scale (McCoy \& Major, 2003) and Bargad and Hyde's (1991) Feminist Identity Development Scale (Moradi \& Subich, 2002; Sabik \& Tylka, 2006). The remaining studies did not specify the identification scale used, or a scale was created for use in the study at hand (Bourguignon, Seron, Yzerbyt, \& Herman, 2006; Major, Quinton, \& Schmader, 2003; Mossakowski, 2003; Noh et al., 1999; Schmitt, Branscombe, Kobrynowica, \& Owen, 2002; Whitbeck, Chen, Hoyt, \& Adams, 2004; D. R. Williams et al., 1999).

A buffering or positive effect was defined as occasions when identification with one's group was related to a decreased impact of perceived discrimination on negative health. Intensified or exacerbated relationships refer to occasions in which identification was related to an increased negative effect of perceived discrimination on health.

Mental health. Twelve articles, with a total of 68 effects, examined the relationship between perceived discrimination and mental health. Twelve (18\%) of the total 68 analyses reported that group identification had a buffering effect on the perceived discrimination-health relationship. This buffering effect was found for mental health indicators such as depressive symptomatology (Jones, Cross, \& DeFour, 2007; Lee, 2005; Mossakowksi, 2003), well-being (Lee, 2003, 2005), self-esteem (Romero \& Roberts, 2003), and perceived stress (Sellers et al., 2003). Eight analyses $(12 \%)$ showed that higher levels of identification led to more negative mental health. This exacerbating effect was found for mental health indicators such as self-esteem (McCoy \& Major, 2003), well-being (Sellers et al., 2006), perceived stress (Sellers et al., 2006), and depression (McCoy \& Major, 2003; Noh et al., 1999; Sellers et al., 2006). The remaining 48 effects (71\%) found no effect of identification on the relationship between perceived discrimination and mental health.

Physical health. Only one study examined the moderating effect of identification on the relationship between perceived discrimination and physical health (D. R. Williams et al., 1999). Looking at the effect of general unfair treatment on self-reported health and chronic health problems, this study reported 14 effects. Only 2 effects showed a buffering relationship for identification; the remaining 12 effects found a null relationship.

Stress responses. One study investigated the moderating relationship between identification, gender discrimination, and psychological stress response over three effects (Major et al., 2003). In this study, identification was not found to buffer or exacerbate the relationship between perceived discrimination and psychological stress response.

Health behaviors. One study examined identification with regard to disordered eating behaviors over 11 effects (Sabik \& Tylka, 2006). Of these 11 effects, 4 (36\%) found that higher levels of identification were related to an attenuation of the perceived discrimination-health behavior relationship. The remaining 7 effects $(64 \%)$ found no relationship. No analyses found that identification exacerbated the link between perceived discrimination and health behaviors.

Across all health outcomes, some of the buffering relationships were found to be conditional on variables such as coping style, level of discrimination stress, and identity complexity. For example, Noh et al. (1999) suggested that the interaction of high identification and the use of forbearance coping buffered the effects of perceived discrimination stress. This was not apparent for low levels of identification. McCoy and Major (2003) found that high levels of identification were related to high self-esteem but only when discrimination was not present. In the presence of discrimination, lower identification levels were related to less depressed emotion and higher self-esteem. Sabik and Tylka (2006) showed that the complexity of identification that individuals have with their group makes a difference as to whether identification with that group will buffer the relationship between perceived discrimination and health. In this study, women who were highly, actively committed to social change for their gender group or who were higher in synthesis (being able to blend female attributes with unique personal qualities) showed more protection against perceiving discrimination than women reporting less engagement with these types of feminist identity.

In terms of exacerbating relationships, one analysis found that higher levels of identification may exacerbate the link between perceived discrimination and health, conditional upon the individuals' identity complexity. Moradi and Subich (2002) found that women who accepted more traditional gender roles (passive acceptance) showed an exacerbated link between perceived discrimination and health.

Overall, these results suggest that increasing levels of identification with one's group may be as likely to serve as a buffer than as an intensifier of the relationship between perceived discrimination and health. The direction of this relationship seems to be dependent on other variables, such as the level of discrimination stress experienced, and identification type and complexity, although often identification did not have an effect on the relationship. Further study of these conditional variables may help tease apart when and why identification might ease or intensify the ill effects of perceiving discrimination upon health.

\section{Discussion}

Although previous research has provided compelling evidence for the harmful effects that perceived discrimination can have on certain health outcomes, there has also been a lack of clarity about the strength of support for these relationships. Furthermore, a theoretical framework to understand the mechanisms underlying these effects has been lacking in the literature. The goal of our analysis was to systematically examine the literature to determine the strength of the evidence for these effects and to test a model that identifies pathways by which perceived discrimination may affect health. We additionally tested for the influence of important covariates and examined various dimensions of types of discrimination. The main premise underlying this meta-analysis was that discriminatory experiences influence health through the stress responses they engender. Through repeated exposure to discrimination, these stress responses-both physiological and psychologi- 
cal-can lead to mental and physical illnesses. The perception of discrimination can also put people at higher risk for engaging in health behaviors that may serve an adaptive, stress-reducing function in the short term but may ultimately increase risk for disease (see also Jackson \& Knight, 2006).

Overall, the results of this analysis supported our model and suggest that increased levels of perceived discrimination are associated with more negative mental and physical health. These results are consistent with previous research showing that perceived discrimination is associated with a variety of negative physical and mental health consequences, including increased psychological distress and increased symptoms of depression ( $\mathrm{T}$. Brown et al., 2000; D. R. Williams \& Mohammed, 2009), and can be conceptualized as a specific form of stress. It is important to note that we also found that the perception of discrimination is related to heightened physiological stress responses, more negative psychological stress responses, increased participation in unhealthy behaviors, and decreased participation in healthy behaviors, suggesting promising avenues for future mediation analyses of these variables. Analysis of covariates using traditional research synthesis found that these relationships remained even when important demographic variables were taken into account.

It is important to note that although a direct causal pathway between perceived discrimination and health could not be determined because of the nonexperimental nature of the included studies, the results of longitudinal studies suggest that our proposed pathway is the most likely direction of the effect. For example, Pavalko, Mossakowski, and Hamilton (2003) found that perceptions of discrimination reported in an initial wave of data were related to mental health reported 7-9 years later, even when controlling for emotional health during the initial data wave. Further, T. Brown et al. (2000) examined the association between perceived discrimination and mental health over time and did not find evidence of an association between psychological distress or depressive symptoms during early waves of data and reports of perceived discrimination 1 year later, suggesting that poor mental health does not predict discrimination perceptions.

Although not tested within this study, the relationships between sustained cardiovascular activity and negative cardiovascular health (see Treiber et al., 2003, for review) and between sustained negative emotional state and mental illness (National Institutes of Health $[\mathrm{NIH}], 2002)$ are well documented in the literature. Treiber et al. (2003) found that in large epidemiological studies following individuals over long periods (20 years or more), the blood pressure responses of initially normotensive individuals to stressinducing manipulations were predictive of subsequent incidence of essential hypertension. Several other studies found an association between cardiovascular reactivity and other subclinical diseases including carotid atherosclerosis and increased left ventricular mass. These results suggest that increases in cardiovascular reactivity may lead to high blood pressure and/or other, more serious cardiovascular disease.

Chronic experiences of stress can also affect the levels of cortisol secreted in the body (Miller, Chen, \& Zhou, 2007). Sustained elevated levels of cortisol in the body are thought to be damaging to tissues and may lead to the dysregulation of biological systems (S. Cohen, Kessler, \& Underwood, 1995). However, other research has found that it is decreased levels of cortisol that are associated with pathology (Heim, Ehlert, \& Hellhammer,
2000). In a meta-analysis on stress and the hypothalamic-pituitaryadrenocortical axis in humans, Miller, Chen, and Zhou (2007) found that for individuals enduring chronic stressors, cortisol levels were higher than normal. For those who experienced an acute stressor, cortisol levels declined to below normal as time elapsed. Another meta-analysis on cortisol response to stress (Dickerson \& Kemeny, 2004) found that experiences of stress tended to increase cortisol levels, and these effects were especially pronounced when the stress was perceived as uncontrollable, as with perceived discrimination. These findings suggest that individuals may be at risk for developing certain diseases, such as depression, schizophrenia, heart disease, and metabolic syndrome, when cortisol levels are elevated (Björntorp \& Rosmond, 1999; Nemeroff, 1996; G. D. Smith et al., 2005; Walker \& Diforio, 1997). However, as time passes and cortisol levels drop below normal, individuals may be more susceptible to other conditions, such as rheumatoid arthritis, fibromyalgia, and allergic conditions (Heim et al., 2000; Raison \& Miller, 2003).

Work by McEwen $(1998,1999)$ on allostatic load suggests that sustained levels of the stress response hormones, glucocorticoid and catecholamines, adaptive in normal levels, may also accelerate disease processes. Allostatic load, or the cost of elevated hormone levels in the body, may lead to the atrophy or death of neurons (McEwen, 1999; Uno, Ross, Else, Suleman, \& Sapolsky, 1989), and if neglected over a long period, allostatic load may lead to a variety of health problems including depression, obesity, and cardiovascular disease (Brindley \& Rolland, 1989; Schulkin, McEwen, \& Gold, 1994; Seeman et al., 1997). This concept is supported by animal research, which supports the hypothesis that stress hormone reactivity in early life can have lifelong consequences.

Mental states caused by stress may also be a pathway by which the perception of discrimination may lead to negative health. For example, Kubzansky et al. (1997) found that worry, which is an important component of anxiety, may have increased the risk of coronary heart disease in a sample of men. Combined, these findings highlight the viability of the link between stress responding to the onset of mental and physical illness: Increased and/or sustained mental and physical responses to stress can lead to negative mental and physical health outcomes.

Similarly, we did not specifically test for the relationship between health-related behaviors and health outcomes, but there is strong evidence for how certain behaviors can negatively impact health, particularly for smoking, excessive drinking, and overeating. Clear links between smoking and disease outcomes such as lung cancer and several other forms of cancer, cardiovascular disease, and strokes are well established (Centers for Disease Control [CDC], 2008; National Center for Health Statistics, 2003; U.S. Department of Health and Human Services, 2004). Harmful effects of excessive alcohol use are also well known. Alcohol use has been cited as the third leading lifestyle-related cause of death for the nation, causing approximately 75,000 deaths in the United States annually (CDC, 2006). Alcohol abuse has been linked to both short-term and long-term illness. Excessive alcohol intake can cause impaired brain function, which results in poor judgment, reduced reaction time, and the loss of balance and motor skills. These impairments can lead to an increased risk of unintentional injuries such as motor-vehicle accidents, falls, drowning, burns, and firearm injuries (G. S. Smith, Branas, \& Miller, 1999) and the 
increased likelihood to engage in risky sexual behavior (Naimi, Lipscomb, Brewer, \& Colley, 2003; Wechsler, Davenport, Dowdall, Moeykens, \& Castillo, 1994). In addition, excessive alcohol use has been linked with long-term illnesses including liver diseases such as hepatitis and cirrhosis (Kochanek, Murphy, Anderson, \& Scott, 2004). Obesity has been identified as a risk factor for developing several serious medical problems including hypertension, dyslipidemia, Type 2 diabetes, coronary heart disease, stroke, gallbladder disease, osteoarthritis, sleep apnea, respiratory problems, and endometrial, breast, prostate, and colon cancers (NIH, 1998).

Past research has also found that when attempting to attain goals, self-regulatory failure may be related to increased feelings of dejection and agitation as well as decreased feelings of cheerfulness and quiescence (Higgins, Shah, \& Friedman, 1997). Other researchers have theorized that depression may have originated as a response to loss or failure to make progress toward goals (Akiskal \& McKinney, 1973; Strauman, 2002). Accumulation of these sorts of failures is thought to lead to more prolonged and severe psychological consequences until the individual can no longer function in a normal fashion (Strauman, 2002). Thus, for individuals who regard healthy living as a goal within their lives, frequent self-regulatory lapses regarding health-related behavior may have a negative effect not only on their physical health but also on their mental health.

Combined, these data highlight the importance of healthy behavior in preventing the onset of disease. The finding that perceived discrimination is associated with individuals' increased participation in unhealthy behaviors and decreased participation in healthy behaviors suggests that health behaviors are part of the pathway by which the experience of perceiving discrimination may be related to negative health outcomes.

\section{Theoretical and Methodological Implications}

Few studies to date have been able to draw causal conclusions about the relationship between perceived discrimination and physical or mental health because of the cross-sectional designs of most of the research in this area. The challenges and shortcomings of manipulating discriminatory experiences in an experimental design are many, but several studies have attempted experimental methods by using videotaped and audiotaped discriminatory scenarios, speech and writing tasks in which past discrimination events are recalled, or actual gender or racial discrimination delivered by a confederate of the study. Further refinement of these manipulations will help produce more insight into the causal nature of this relationship, but one suggestion is that careful manipulation checks and post hoc questioning of participants be performed by experimenters to fully understand how the manipulations are experienced. In one experimental study, Merritt, Bennett, Williams, Edwards, \& Sollers (2006) assigned participants to listen to a blatantly racist discriminatory encounter or the same situation without reference to race. The unusual finding that individuals in the nonracist condition were showing more increased cardiovascular response than those in the blatantly racist condition alerted the researchers to examine the nonracist condition more closely. They found that most of the individuals in the nonracist condition perceived at least some racial discrimination within the audiotaped scenario even though none was explicitly present, with some participants perceiving extremely high levels of racist discrimination. In addition to highlighting how perceptions of discrimination within ambiguous situations may influence physiological responding, this study indicates the importance of checking manipulations of discrimination to ensure that they function as intended.

Another important area of future inquiry is the synergistic effects of mental and physical health outcomes. Depression has been related to suppressed immune functioning (see Robles, Glaser, \& Kiecolt-Glaser, 2005), emotional distress has been related to elevations in cortisol and other neuroendocrines (Dickerson \& Kemeny, 2004), and symptoms of anxiety and depression predict future incidence of coronary heart disease (Kubzansky et al., 1997). In addition, increases in discriminatory experiences over time are associated with subsequent deteriorations in physical and mental health (Schulz et al., 2006). However, not all research has found this pattern. Caputo (2003), in an analysis of youth over time, found that although perceived discrimination was related to decrements in mental health over time, it was not related to decreased physical health.

The effect of discrimination measurement type could not be fully analyzed within this analysis, but our results suggest the importance of closely examining recent and chronic stress in relationship to discrimination stress. We found that the point estimate for recent discrimination's relationship with mental health was nearly twice that of the same analysis with lifetime discrimination. Although no other measurement analyses were significant, recent and chronic discrimination estimates were consistently more negative than those for lifetime discrimination, implying that these types of discrimination stress may have the most deleterious effects on health outcomes. Models of stress and coping (e.g., Lazarus \& Folkman, 1984) suggest that forming a clear mental representation of a stressor facilitates coping and reduces stress. Subtle forms of discrimination may produce more stress because of their ambiguous nature. When an individual is subjected to subtle mistreatment, it may be unclear as to what underlies the behavior, and as a result, the individual may have difficulty deciding on a coping response (e.g., D. R. Williams et al., 2003).

\section{Influence of Covariates}

Analysis of commonly included moderators of the perceived discrimination-health link revealed some relatively weak patterns, with most analyses reporting null results. However, for those results that were significant, social support was more likely to buffer the relationship between perceived discrimination and negative mental health, supporting the notion that individuals with strong social support networks may be able to offset the pernicious effects of discrimination through close connections with others, although this relationship was the opposite for physical health. However, several of these relationships were conditional, suggesting that the type of social support sought, the specific health outcome studied, or the amount of discrimination stress experienced by individuals may affect whether this relationship is found An important area of future research will be to examine these conditional results more fully to determine more precisely the role of social support in the discrimination experience.

Similar analyses on coping suggest that not all coping behaviors are equally successful in decreasing the effect of perceived dis- 
crimination on negative health. Although most results showed null effects, for those results that were significant, active or problemfocused coping seemed to be the most effective type of coping, with all significant effects showing a buffering effect and no evidence of exacerbation of the effect of discrimination stress on health. Conversely, passive or emotion-focused coping seemed to be much less effective at dealing with discrimination stress, with the majority of significant effects examined showing an exacerbating effect. However, conditional results suggest that the most effective way of coping with discrimination stress may vary by ethnicity, culture, and gender. For example, the John Henryism hypothesis suggests that active coping may be deleterious for Black men but beneficial for Black women (S. A. James, 1994). Passive coping, although generally found to be detrimental, was the most beneficial type of coping for Asians in another study, though less so for Asians who had been acculturated to American society for a longer period (Noh et al., 1999; Noh \& Kaspar, 2003). These differences in ethnicity, culture, and gender should be examined more closely by future researchers as a way to understand how certain coping responses to discrimination can be more effective than others.

Analysis of the moderating effect of group identification on the discrimination-health relationship suggests weak effects, with most effects studied showing null results. For those that were significant, approximately $60 \%$ revealed that high group identification was more likely to alleviate the negative effect of perceived discrimination, whereas the remaining $40 \%$ showed the opposite effect. However, the conditional nature of these results suggests that the beneficial nature of being highly identified with one's group may vary by coping style, level of discrimination stress, and complexity of that identity. For example, although group identity, when found to have a significant effect, is generally found to be beneficial, in one study, individuals with a strong group identity who coped in a passive fashion reported lower self-esteem when reports of discrimination were high (Noh et al., 1999). This relationship was reversed when reports of discrimination were low. In addition, Sabik and Tylka (2006) found that highly genderidentified women with more complex identities were more protected from the effect of discrimination on health than women with less complex gender identities. These variations of responses based on level of perceived discrimination, identity complexity, and the interaction between identification and coping style provide ample avenues for future research to investigate these differences more closely.

\section{Limitations}

These analyses did not include several potentially influential covariates and moderator variables in many of the models. Although this is partially due to the limits of meta-analysis itself, current conventions of data reporting were also a limiting factor. However, these limitations can be circumvented in the future if some convention is established as to the inclusion of certain choice variables in an initial model. For example, meta-analysis might be able to separate perceived discrimination's correlation with health from the effects of age, education, income, and race if the majority of researchers examined the effects of perceived discrimination on health within a multiple regression model that included only perceived discrimination, age, education, income, and race before testing their secondary models. Similarly, if researchers presented partial correlations using a specified set of control variables, metaanalysts might be better able to isolate the direct relationship between perceived discrimination and health. Although this is a lofty goal, without it only the zero-order relationship between perceived discrimination and health effects can be statistically observed within a meta-analysis. For researchers interested in estimating the effect of variables such as social support, coping, and ethnic identity on the perceived discrimination-health link, consistently providing a simple regression model or partial correlation table including these variables before testing a fuller model might allow for meta-analysts to partial out these effects in the future. Until researchers agree to report results within a framework that involves consistent reporting of certain important variables (such as within a partial correlation table or a regression analysis step involving certain important covariates), the true magnitude of the perceived discrimination-health link will not be completely measurable through meta-analytic procedures.

Because variables that might have influenced the perceived discrimination-health relationship did not qualify for our analysis and thus were excluded, it is likely that the average weighted correlation produced by this analysis is a somewhat inflated estimate of the actual relationship between perceived discrimination and health. However, examination of our results in conjunction with those of multivariate models helps to strengthen the conclusions made here: The majority of associations within multivariate frameworks showed an association between increased levels of perceived discrimination and poorer health even with the inclusion of common covariates.

The same shortcoming may hold for the inability to include variables that might moderate the perceived discrimination-health link, such as social support, ethnic identity, and coping style. Despite their noninclusion, it is likely that these variables (and others such as mastery, neuroticism, hostility, and optimism) do have a considerable influence on this association between perceived discrimination and health. However, the nature of data presentation in the literature did not allow for the analysis of these relationships. To compensate for this limitation, we summarized studies that examined these three variables in relationship to perceived discrimination and health outcomes and identified patterns instead.

In addition, because of the relatively small number of studies using experimental or longitudinal designs, directional arrows for many of this study's pathways could not be fully determined. However, studies that have used longitudinal and experimental designs (e.g., T. Brown et al., 2000; Pavalko et al., 2003) suggest that the pathways are in the directions suggested by our model.

Finally, it should also be noted that the conclusions we draw from our meta-analysis are based on a disproportionate number of studies that examine race-based discrimination. It may very well be the case that different types of discrimination are related to different outcomes, with some having more detrimental effects than others. As yet, the research in this area has not accounted for potential distinctions among types of discrimination within one research study that would enable a direct comparison of effects. The effects we found were in the same direction across all outcomes, however, regardless of type of discrimination (gender, sexual, unspecified discrimination, and unfair treatment were the others we examined) providing support for the potential general- 
izability of these findings beyond racial discrimination. Major et al. (2002) provided some discussion of this issue in which they review research findings that members of stigmatized groups can exhibit both vulnerability and resilience in response to discrimination depending on a number of internal and contextual factors. As the literature in the field develops, a more comprehensive understanding of potential moderators of this effect is important to pursue. As Major et al. noted, group status may be important to consider, because the experience of discrimination is less likely to be stressful if the target has control over important resources or has the ability to avoid exposure to prejudiced individuals. However, we caution against attempts to make generalizations as to whether one type of discrimination may have more harmful effects than another type; changing contexts, power structures, intensity, duration, social support, and a host of other potential factors make such conclusions highly speculative.

\section{Summary and Conclusions}

Overall, the results of this analysis have supported previous researchers' hypotheses that perceived discrimination may be related to both mental and physical health outcomes. In addition, our analysis provides evidence that this relationship may occur through the mechanisms of stress responses and health behaviors. These relationships remained even when important covariates were included in the analyses. Our synthesis of existing literature also suggests that social support, active coping styles, and group identification were most likely to serve a protective function in these pathways. Our findings refine the knowledge base in this area and guide a more mechanistic research agenda. We clarify some of these long-standing questions in the literature and suggest methodological strategies for how this research is conducted and interpreted in the future.

\section{References}

References marked with an asterisk indicate studies included in the meta-analysis. Those marked with a dagger indicate studies included in the multivariate review.

${ }^{\dagger}$ Ahern, J., Stuber, J., \& Galea, S. (2007). Stigma, discrimination and the health of illicit drug users. Drug and Alcohol Dependence, 88, 188-196.

Akiskal, H. S., \& McKinney, W. T. (1973, October 5). Depressive disorders: Toward a unified hypothesis. Science, 182, 20-29.

`Amaro, H., Russo, N. F., \& Johnson, J. (1987). Family and work predictors of psychological well-being among Hispanic women professionals. Psychology of Women Quarterly, 11, 505-521.

* Ashburn-Nardo, L., Monteith, M. J., Arthur, S. A., \& Bain, A. (2007). Race and the psychological health of African Americans. Group Processes \& Intergroup Relations, 10(4), 471-491.

${ }^{\dagger}$ Banks, K. H., \& Kohn-Wood, L. P. (2007). The influence of racial identity profiles on the relationship between racial discrimination and depressive symptoms. Journal of Black Psychology, 33, 331-354.

*'Banks, K. H., Kohn-Wood, L. P., \& Spencer, M. (2006). An examination of the African American experience of everyday discrimination and symptoms of psychological distress. Community Mental Health Journal, 42(6), 555-569.

Bargad, A., \& Hyde, J. S. (1991). Women's studies: A study of feminist identity development in women. Psychology of Women Quarterly, 15, 181-201.

"Barnes, L. L., Mendes De Leon, C. F., Wilson, R. S., Bienias, J. L., Bennett, D. A., \& Evans, D. A. (2004). Racial differences in perceived discrimination in a community population of older Blacks and Whites. Journal of Aging and Health, 16(3), 315-337.

${ }^{*}$ B Barnes, P. W., \& Lightsey, O. R., Jr. (2005). Perceived racist discrimination, coping, stress, and life satisfaction. Journal of Multicultural Counseling and Development, 33, 48-61.

Barnett, R. C., Marshall, N. L., \& Sayer, A. (1997). The changing workforce, job stress, and psychological distress. Journal of Occupational Health Psychology, 2(2), 99-107.

*Barrett, M. E., Joe, G. W., \& Simpson, D. D. (1991). Acculturation influences on inhalant use. Hispanic Journal of Behavioral Sciences, 13(3), 276-296.

'Beiser, M., \& Hou, F. (2006). Ethnic identity, resettlement stress and depressive affect among Southeast Asian refugees in Canada. Social Science \& Medicine, 63, 137-150.

Bennett, G. G., Wolin, K. Y., Robinson, E. L., Fowler, S., \& Edwards, C. L. (2005). Racial/ethnic harassment and tobacco use among African American young adults. American Journal of Public Health, 95(2), $238-240$.

${ }^{*}{ }^{\star}$ Bianchi, F. T., Zea, M. C., Poppen, P. J., Reisen, C. A., \& Echeverry, J. J. (2004). Coping as a mediator of the impact of sociocultural factors on health behaviour among HIV-positive Latino gay men. Psychology \& Health, 19(1), 89-101.

* Bierman, A. (2006). Does religion buffer the effects of discrimination on mental health? Differing effects by race. Journal for the Scientific Study of Religion, 45(4), 551-565.

*Bird, S. T., Bogart, L. M., \& Delahanty, D. L. (2004). Health-related correlates of perceived discrimination in HIV care. AIDS Patient Care and STDs, 18(1), 19-26.

Björntorp, P., \& Rosmond, R. (1999). Hypothalamic origin of the Metabolic Syndrome X. Annals of the New York Academy of Sciences, 892, 297-307.

*'Bond, M. A., Punnett, L., Pyle, J. L., Cazeca, D., \& Copperman, M. (2004). Gendered work conditions, health, and work outcomes. Journal of Occupational Health Psychology, 9(1), 28-45.

Borenstein, M., Hedges, L., Higgins, J., \& Rothstein, H. (2005). Comprehensive Meta-Analysis (Version 2.2.040) [Computer software]. Englewood, NJ: Biostat.

Borrell, L. N., Jacobs, D. R., Jr., Williams, D. R., Pletcher, M. J., Houston, T. K., \& Kiefe, C. I. (2007). Self-reported racial discrimination and substance use in the Coronary Artery Risk Development in Adults Study. American Journal of Epidemiology, 166(9), 1068-1079.

* Borrell, L. N., Kiefe, C. I., Williams, D. R., Diez-Roux, A. V., \& Gordon-Larsen, P. (2006). Self-reported health, perceived racial discrimination, and skin color in African Americans in the CARDIA study. Social Science \& Medicine, 63, 1415-1427.

* ${ }^{\dagger}$ Bourguignon, D., Seron, E., Yzerbyt, V., \& Herman, G. (2006). Perceived group and personal discrimination: Differential effects on personal self-esteem. European Journal of Social Psychology, 36, 773-789.

${ }^{*}$ Branscombe, N. R., Schmitt, M. T., \& Harvey, R. D. (1999). Perceiving pervasive discrimination among African Americans: Implications for group identification and well-being. Journal of Personality and Social Psychology, 77(1), 135-149.

Brindley, D., \& Rolland, Y. (1989). Possible connections between stress, diabetes, obesity, hypertension and altered lipoprotein metabolism that may result in atherosclerosis. Clinical Science, 77, 453-461.

* Brody, G. H., Chen, Y., Murry, V. M., Simons, R. L., Ge, X., Gibbons, F. X., et al. (2006). Perceived discrimination and the adjustment of African American youths: A five-year longitudinal analysis with contextual moderation effects. Child Development, 77(5), 1170-1189.

${ }^{*}$ Broman, C. L. (1997). Race-related factors and life satisfaction among African Americans. Journal of Black Psychology, 23(1), 36-49.

'Broman, C. L., Mavaddat, R., \& Hsu, S. (2000). The experiences and consequences of perceived racial discrimination: A study of African Americans. Journal of Black Psychology, 26(2), 165-180. 
Brondolo, E., Libby, D. J., Denton, E., Thompson, S., Beatty, D. L., Schwartz, J., et al. (2008). Racism and ambulatory blood pressure in a community sample. Psychosomatic Medicine, 70, 49-56.

${ }^{\dagger}$ Broudy, R., Brondolo, E., Coakley, V., Brady, N., Cassells, A., Tobin, J. N., \& Sweeney, M. (2007). Perceived ethnic discrimination in relation to daily moods and negative social interactions. Journal of Behavioral Medicine, 30(1), 31-43.

*Brown, C., Matthews, K. A., Bromberger, J. T., \& Chang, Y. (2006). The relation between perceived unfair treatment and blood pressure in a racially/ethnically diverse sample of women. American Journal of Epidemiology, 16(3), 257-262.

'Brown, T., Williams, D. R., Jackson, J. J., Neighbors, H. W., Torres, M., Sellers, S. L., \& Brown, K. T. (2000). "Being Black and feeling blue": The mental health consequences of racial discrimination. Race \& Society, 2(2), 117-131.

*'Bynum, M. S., Burton, E. T., \& Best, C. (2007). Racism experiences and psychological functioning in African American college freshmen: Is racial socialization a buffer? Cultural Diversity and Ethnic Minority Psychology, 13(1), 64-71.

*'Campbell, R. E. R. (2000). The effect of sexist discrimination on women's health (Doctoral dissertation, Loma Linda University, 2000). Dissertation Abstracts International, 61(4-B), 2192.

* Caputo, R. K. (2003). The effects of socioeconomic status, perceived discrimination and mastery on health status in a youth cohort. Social Work in Health Care, 37(2), 17-42.

* Cassidy, C., O’Connor, R. C., How, C., \& Warden, D. (2005). Perceived discrimination among ethnic minority young people: The role of psychological variables. Journal of Applied Social Psychology, 35(6), $1246-1265$.

Centers for Disease Control and Prevention. (2006). Quick stats: General information on alcohol use and health. Retrieved from http:// www.cdc.gov/alcohol/quickstats/general_info.htm

Centers for Disease Control and Prevention. (2008). Fact sheet: Health effects of cigarette smoking. Retrieved from http://www.cdc.gov/ tobacco/Data_statistics/fact_sheets/health_effects/health_effects.htm

* Chávez, N. R., \& French, S. E. (2007). Ethnicity-related stressors and mental health in Latino Americans: The moderating role of parental racial socialization. Journal of Applied Social Psychology, 37(9), 19741998.

${ }^{\dagger}$ Chen, A. C.-C., Keith, V. M., Airriess, C., Li, W., \& Leong, K. J. (2007). Economic vulnerability, discrimination, and Hurricane Katrina: Health among Black Katrina survivors in eastern New Orleans. Journal of the American Psychiatric Nurses Association, 13(5), 257-266.

*Clark, R. (2000). Perceptions of interethnic group racism predict increased vascular reactivity to a laboratory challenge in college women. Annals of Behavioral Medicine, 22(3), 214-222.

${ }^{*}$ Clark, R. (2003). Self-reported racism and social support predict blood pressure reactivity in Blacks. Annals of Behavioral Medicine, 25(2), 127-136.

${ }^{*}$ Clark, R. (2006a). Interactive but not direct effects of perceived racism and trait anger predict resting systolic and diastolic blood pressure in Black adolescents. Health Psychology, 25(5), 580-585.

${ }^{\dagger}$ Clark, R. (2006b). Perceived racism and vascular reactivity in Black college women: Moderating effects of seeking social support. Health Psychology, 25(1), 20-25.

${ }^{\dagger}$ Clark, R., \& Adams, J. H. (2004). Moderating effects of perceived racism on John-Henryism and blood pressure reactivity in Black female college students. Annals of Behavioral Medicine, 28(2), 126-131.

Clark, R., Anderson, N. B., Clark, V. R., \& Williams, D. R. (1999). Racism as a stressor for African Americans: A biopsychosocial model. American Psychologist, 54(10), 805-816.

Cohen, J. (1988). Statistical power analysis for the behavioral sciences. Hillsdale, NJ: Erlbaum.

Cohen, S., Kessler, R. C., \& Underwood, L. G. (1995). Strategies for measuring stress in studies of psychiatric and physical disorders. In S. Cohen, R. C. Kessler, \& L. G. Underwood (Eds.), Measuring stress: A guide for health and social scientists (pp. 3-28). New York: Oxford University Press.

${ }^{\dagger}$ Combs, D. R., Penn, D. L., Cassisi, J., Michael, C., Wood, T., Wanner, J., \& Adams, S. (2006). Perceived racism as a predictor of paranoia among African Americans. Journal of Black Psychology, 32(1), 87-104.

Cooper, H. M. (1998). Synthesizing research: A guide for literature reviews (3rd ed.). Thousand Oaks, CA: Sage.

Cooper, H., Civey Robinson, J., \& Patall, E. A. (2006). Does homework improve academic achievement? A synthesis of research, 1987-2003. Review of Educational Research, 76(1), 1-62.

${ }^{* \dagger}$ Corning, A. F. (2002). Self-esteem as a moderator between perceived discrimination and psychological distress among women. Journal of Counseling Psychology, 49(1), 117-126.

'Dambrun, M. (2007). Gender differences in mental health: The mediating role of perceived personal discrimination. Journal of Applied Social Psychology, 37(5), 1118-1129.

${ }^{\dagger}$ Diaz, R. M., Ayala, G., \& Bien, E. (2004). Sexual risk as an outcome of social oppression: Data from a probability sample of Latino gay men in three U.S. cities. Cultural Diversity and Ethnic Minority Psychology, 10(3), 255-267.

'Diaz, R. M., Ayala, G., Bein, E., Henne, J., \& Marin, B. V. (2001). The impact of homophobia, poverty, and racism on the mental health of gay and bisexual Latino gay men: Findings from US cities. American Journal of Public Health, 91(6), 927-932.

Dickerson, S. S., \& Kemeny, M. E. (2004). Acute stressors and cortisol responses: A theoretical integration and synthesis of laboratory research. Psychological Bulletin, 130(3), 355-391.

*Dietch, E. A., Barsky, A., Butz, R. M., Chan, S., Breif, A. P., \& Bradley, J. C. (2003). Subtle yet significant: The existence and impact of everyday racial discrimination in the workplace. Human Relations, 56(11), 1299-1324.

Digby, P. G. N. (1983). Approximating the tetrachoric correlation coefficient. Biometrics, 39, 753-757.

*Din-Dzietham, R., Nembhard, W. N., Collins, R., \& Davis, S. K. (2004). Perceived stress following race-based discrimination at work is associated with hypertension in African-Americans. The metro Atlanta heart disease study, 1999-2001. Social Science \& Medicine, 58, 449-461.

*Dion, K. L., Dion, K. K., \& Pak, A. W. (1992). Personality-based hardiness as a buffer for discrimination-related stress in members of Toronto's Chinese community. Canadian Journal of Behavioural Science, 24(4), 517-536.

Duval, S., \& Tweedie, R. (2000a). A nonparametric "trim and fill" method of accounting for publication bias in meta-analysis. Journal of the American Statistical Association, 95, 89-98.

Duval, S., \& Tweedie, R. (2000b). Trim and fill: A simple funnel plotbased method of testing and adjusting for publication bias in metaanalysis. Biometrics, 56, 276-284.

*Eccleston, C. P., \& Major, B. N. (2006). Attributions to discrimination and self-esteem: The role of group identification and appraisals. Group Processes \& Intergroup Relations, 9, 147-162.

Egger, M., Davey Smith, G., Schneider, M., \& Minder, C. (1997). Bias in meta-analysis detected by a simple graphical test. British Medical Journal, 315, 629-634.

Finch, B. K., Catalano, R. C., Novaco, R. W., \& Vega, W. A. (2003). Employment frustration and alcohol abuse/dependence among labor migrants in California. Journal of Immigrant Health, 5(4), 181-186.

${ }^{\dagger}$ Finch, B. K., Hummer, R. A., Kolody, B., \& Vega, W. A. (2001). The role of discrimination and acculturative stress in the physical health of Mexican-origin adults. Hispanic Journal of Behavioral Sciences, 23(4), 399-429.

†Finch, B. K., Kolody, B., \& Vega, W. A. (2000). Perceived discrimination 
and depression among Mexican-origin adults in California. Journal of Health and Social Behavior, 41(3), 295-313.

${ }^{*}$ Fischer, A. R., \& Holz, K. B. (2007). Perceived discrimination and women's psychological distress: The roles of collective and personal self-esteem. Journal of Counseling Psychology, 54(2), 154-164.

*'Fischer, A. R., \& Shaw, C. M. (1999). African Americans' mental health and perceptions of racist discrimination: The moderating effects of racial socialization experiences and self-esteem. Journal of Counseling Psychology, 46(3), 395-407.

*Fisher, C. B., Wallace, S. A., \& Fenton, R. E. (2000). Discrimination distress during adolescence. Journal of Youth and Adolescence, 29(6), 679-695.

${ }^{\dagger}$ Forman, T. A. (2003). The social psychological costs of racial segmentation in the workplace: A study of African Americans' well-being. Journal of Health and Social Behavior, 44(3), 332-352.

${ }^{\dagger}$ Foster, M. D., Choma, B. L., \& Hitchcock, S. (2007). Coping with discrimination: Differences between White and visible. Unpublished manuscript.

†Foster, M. D., Jackson, L. C., Hartmann, R., \& Woulfe, S. (2004). Minimizing the pervasiveness of women's personal experiences of gender discrimination. Psychology of Women Quarterly, 28, 224-232.

* Foster, M. D., Sloto, L., \& Ruby, R. (2006). Responding to discrimination as a function of meritocracy beliefs and personal experiences: Testing the model of shattered assumptions. Group Processes \& Intergroup Relations, 9(3), 401-411.

*Foster, M. D., \& Tsarfati, E. M. (2005). The effects of meritocracy beliefs on women's well-being after first-time gender discrimination. Personality and Social Psychology Bulletin, 31(12), 1730-1738.

${ }^{*}$ Frable, D. E. S., Wortman, C., \& Joseph, J. (1997). Predicting selfesteem, well-being, and distress in a cohort of gay men: The importance of cultural stigma, personal visibility, community networks, and positive identity. Journal of Personality, 65(3), 599-624.

${ }^{\dagger}$ Franzini, L., \& Fernandez-Esquer, M. E. (2004). Socioeconomic, cultural, and personal influences on health outcomes in low income Mexicanorigin individuals in Texas. Social Science \& Medicine, 29, 1629-1646.

* Garstka, T. A., Schmitt, M. T., Branscombe, N. R., \& Hummert, M. L. (2004). How young and older adults differ in their responses to perceived age discrimination. Psychology and Aging, 19(2), 326-335.

${ }^{\dagger}$ Gee, G. C. (2002). A multilevel analysis of the relationship between institutional and individual racial discrimination and health status. American Journal of Public Health, 92(4), 615-623.

${ }^{\dagger}$ Gee, G. C., Delva, J., \& Takeuchi, D. T. (2007). Relationships between self-reported unfair treatment and prescription medication use, illicit drug use, and alcohol dependence among Filipino Americans. American Journal of Public Health, 97(5), 933-940.

${ }^{*}$ Gee, G. C., Spencer, M., Chen, J., \& Takeuchi, D. (2007). A nationwide study of discrimination and chronic health conditions among Asian Americans. American Journal of Public Health, 97(7), 1275-1282.

* Gee, G. C., Spencer, M., Chen, J., Yip, T., \& Takeuchi, D. T. (2007). The association between self-reported racial discrimination and 12-month DSM-IV mental disorders among Asian Americans nationwide. Social Science \& Medicine, 64(10), 1984-1996.

* Gibbons, F. X., Gerrard, M., Cleveland, M. J., Wills, T. A., \& Brody, G. (2004). Perceived discrimination and substance use in African American parents and their children: A panel study. Journal of Personality and Social Psychology, 86(4), 517-529.

${ }^{\dagger}$ Gold, N. (2004). Sexism and antisemitism as experienced by Canadian Jewish women: Results of a national study. Women's Studies International Forum, 27, 55-74.

* Goldenhar, L. M., Swanson, N. G., Hurrell, J. J., Ruder, A., \& Deddens, J. (1998). Stressors and adverse outcomes for female construction workers. Journal of Occupational Health Psychology, 3(1), 19-32.

*Greene, M. L., Way, N., \& Pahl, K. (2006). Trajectories of perceived adult and peer discrimination among Black, Latino, and Asian American adolescents: Patterns and psychological correlates. Developmental Psychology, 42(2), 218-238.

${ }^{*}{ }^{\dagger}$ Guthrie, B. J., Young, A. M., Williams, D. R., Boyd, C. J., \& Kintner, E. K. (2002). African American girls' smoking habits and day-to-day experiences with racial discrimination. Nursing Research, 51(3), 183190.

Guttieres, S. E., Saenz, D. S., \& Green, B. L. (1994). Job stress and health outcomes among White and Hispanic employees: A test of the PersonEnvironment Fit Model. In G. P. Keita \& J. J. Hurrell Jr. (Eds.), Job stress in a changing workforce: Investigating gender, diversity, and family issues (pp. 107-125). Washington, DC: American Psychological Association.

Guyll, M., Matthews, K. A., \& Bromberger, J. T. (2001). Discrimination and unfair treatment: Relationship to cardiovascular reactivity among African American and European American women. Health Psychology, 20(5), 315-325.

${ }^{*}$ Harris, R., Tobias, M., Jeffreys, M., Waldegrave, K., Karlsen, S., \& Nazroo, J. (2006). Racism and health: The relationship between experience of racial discrimination and health in New Zealand. Social Science \& Medicine, 63, 1428-1441.

${ }^{*}$ Heckman, T. G. (2003). The Chronic Illness Quality of Life (CIQOL) model: Explaining life satisfaction in people living with HIV disease. Health Psychology, 22(2), 140-147.

${ }^{*}$ Heckman, T. G., Kochman, A., \& Sikkema, K. J. (2002). Depressive symptoms in older adults living with HIV disease: Application of the Chronic Illness Quality of Life Model. Journal of Mental Health and Aging, 8(4), 267-279.

Heim, C., Ehlert, U., \& Hellhammer, D. (2000). The potential role of hypocortisolism in the pathophysiology of stress-related bodily disorders. Psychoneuroendocrinology, 25, 1-35.

Higgins, E. T., Shah, J., \& Friedman, R. (1997). Emotional responses to goal attainment: Strength of regulatory focus as moderator. Journal of Personality and Social Psychology, 72(3), 515-525.

${ }^{*}{ }^{\dagger}$ Hill, L. K., Kobayashi, I., \& Hughes, J. W. (2007). Perceived racism and ambulatory blood pressure in African American college students. Journal of Black Psychology, 33, 404-420.

*Hocoy, D. (1997). Apartheid, racism, and Black mental health in South Africa, and the role of racial identity (Doctoral dissertation, Queen's University, Ontario, Canada, 1997). Dissertation Abstracts International, 58(10-B), 5699.

${ }^{*}{ }^{\dagger}$ Hoyt, C. L., Aguilar, L., Kaiser, C. R., \& Blascovich, J. (2007). The self-protective and undermining effects of attributional ambiguity. Unpublished manuscript.

${ }^{*}$ Huebner, D. M. (2002). Mental and physical health consequences of perceived discrimination (Doctoral dissertation, Arizona State University, 2002). Dissertation Abstracts International, 63(2-B), 1030.

${ }^{*}$ Huebner, D. M., \& Davis, M. C. (2007). Perceived antigay discrimination and physical health outcomes. Health Psychology, 26(5), 627-634.

${ }^{*}{ }^{\dagger}$ Huebner, D. M., Nemeroff, C. J., \& Davis, M. C. (2005). Do hostility and neuroticism confound associations between perceived discrimination and depressive symptoms? Journal of Social and Clinical Psychology, 24(5), 723-740.

${ }^{\dagger}$ Huebner, D. M., Rebchook, G. M., \& Kegeles, S. M. (2004). Experiences of harassment, discrimination, and physical violence among young gay and bisexual men. American Journal of Public Health, 94(7), 12001203.

${ }^{\dagger}$ Inman, M., Barney, C., Izenbaard, N., \& West, A. (2007, May). Cardiovascular reactivity in perceiving stress and perceiving racism. Paper presented at the annual meeting of the Midwestern Psychological Association, Chicago, IL.

Inzlicht, M., McKay, L., \& Aronson, J. (2006). Stigma as ego depletion: How being the target of prejudice affects self-control. Psychological Science, 17(3), 262-269.

*†'Iyer, D. S., \& Haslam, N. (2003). Body image and eating disturbance 
among South Asian-American women: The role of racial teasing. Eating Disorders, 34, 142-147.

* Jackson, J. S., Brown, T. N., Williams, D. R., Torres, M., Sellers, S. L., \& Brown, K. (1996). Racism and the physical and mental health status of African Americans: A thirteen year national panel study. Ethnicity \& Disease, 6(1-2), 132-147.

$\dagger$ Jackson, J. S., \& Inglehart, M. R. (1995). Reverberation theory: Stress and racism in hierarchically structured communities. In S. E. Hobfoll \& M. W. de Vries (Eds.), Extreme stress and communities: Impact and intervention (pp. 353-373). Dordrecht, the Netherlands: Kluwer Academic.

Jackson, J. S., \& Knight, K. M. (2006). Race and self-regulatory health behaviors: The role of the stress response and the HPA axis in physical and mental health disparities. In K. W. Schaie \& L. L. Carstensen (Eds.), Social structure, aging, and self-regulation in the elderly (pp. 189-208). New York: Springer.

* Jackson, P. B., \& Mustillo, S. (2001). I am woman: The impact of social identities on African American women's mental health. Women \& Health, 32(4), 33-59.

*广James, K., Lovato, C., \& Khoo, G. (1994). Social identity correlates of minority workers' health. Academy of Management Journal, 37(2), 383-396.

James, S. A. (1994). John Henryism and the health of African-Americans. Culture, Medicine, and Psychiatry, 18, 163-182.

†Jasinskaja-Lahti, I. (2006). Perceived discrimination and well-being: A victim study of different immigrant groups. Journal of Community \& Applied Social Psychology, 16(4), 267-284.

* Jasinskaja-Lahti, I., \& Liebkind, K. (2007). A structural model of acculturation and well-being among immigrants from the former USSR in Finland. European Psychologist, 12(2), 80-92.

*'Jasinskaja-Lahti, I., Liebkind, K., \& Perhoniemi, R. (2007). Perceived ethnic discrimination at work and well-being of immigrants in Finland: The moderating role of employment status and work-specific grouplevel control beliefs. International Journal of Intercultural Relations, 31, 223-242.

†Jetten, J., Branscombe, N. R., Schmitt, M. T., \& Spears, R. (2001). Rebels with a cause: Group identification as a response to perceived discrimination from the mainstream. Personality and Social Psychology Bulletin, 27(9), 1204-1213.

*'Jones, H. L., Cross, W. E., Jr., \& DeFour, D. C. (2007). Race-related stress, racial identity attitudes, and mental health among Black women. Journal of Black Psychology, 33, 208-231.

†Kaiser, C. R., Major, B., \& McCoy, S. K. (2004). Expectations about the future and the emotional consequences of perceiving prejudice. Personality and Social Psychology Bulletin, 30(2), 173-184.

*Karlsen, S., \& Nazroo, J. (2002). Agency and structure: The impact of ethnic identity and racism on the health of ethnic minority people. Sociology of Health \& Illness, 2(1), 1-20.

*Karlsen, S., \& Nazroo, J. (2006). Fear of racism and health. Journal of Epidemiology and Community Health, 58, 1017-1018.

* Kessler, R. C., Mickelson, K. D., \& Williams, D. R. (1999). The prevalence, distribution, and mental health correlates of perceived discrimination in the United States. Journal of Health and Social Behavior, 40(3), 208-230.

* King, K. R. (1999). The role of multiple group identities in the experience of discrimination: African-American women's attributions to prejudice (Doctoral dissertation, University of California, 1998). Dissertation Abstracts International, 59(9-B), 5167.

* King, K. R. (2003). Racism or sexism? Attributional ambiguity and simultaneous membership in multiple oppressed groups. Journal of Applied Social Psychology, 33(2), 223-247.

* King, K. R. (2005). Why is discrimination stressful? The mediating role of cognitive appraisal. Cultural Diversity and Ethnic Minority Psychology, 11(3), 202-212.
*Klonoff, E. A., Landrine, H., \& Campbell, R. (2000). Sexist discrimination may account for well-known gender differences in psychiatric symptoms. Psychology of Women Quarterly, 24, 93-99.

Kochanek, K. D., Murphy, S. C., Anderson, R. N., \& Scott, C. (2004). Deaths: Final data for 2002. National Vital Statistics Reports, 53(5). Retrieved from http://www.cdc.gov/nchs/data/nvsr/nvsr53/nvsr53_05.pdf

Kubzansky, L. D., Kawachi, I., Spiro, A., III, Weiss, S. T., Vokonoas, P. S., \& Sparrow, D. (1997). Is worrying bad for your heart? A prospective study of worry and coronary heart disease in the Normative Aging Study. Circulation, 95, 818-824.

*Kwate, N. O. A., Valdimarsdottir, H. B., Guevarra, J. S., \& Bovbjerg, D. H. (2003). Experiences of racist events are associated with negative health consequences for African American women. Journal of the $\mathrm{Na}$ tional Medical Association, 95(6), 450-460.

${ }^{*}$ Lam, B. T. (2007). Impact of perceived racial discrimination and collective self-esteem on psychological distress among VietnameseAmerican college students: Sense of coherence as mediator. American Journal of Orthopsychiatry, 77(3), 370-376.

*Landrine, H., \& Klonoff, E. A. (1996). The Schedule of Racist Events: A measure of racial discrimination and a study of its negative physical and mental health consequences. Journal of Black Psychology, 22(2), 144168.

*Lawson, E. J., Rodgers-Rose, L. F., \& Rajaram, S. (1999). The psychosocial context of Black women's health. Health Care for Women International, 20, 279-289.

Lazarus, R. S., \& Folkman, S. (1984). Stress, appraisal, and coping. New York: Springer.

${ }^{*}$ Lee, R. M. (2003). Do ethnic identity and other-group orientations protect against discrimination for Asian Americans? Journal of Counseling Psychology, 50(2), 133-141.

${ }^{*}$ Lee, R. M. (2005). Resilience against discrimination: Ethnic identity and other-group orientation as protective factors for Korean Americans. Journal of Counseling Psychology, 52(1), 36-44.

${ }^{*}$ Lee, R. M., Yoo, H. C., \& Roberts, S. (2004). The coming of age of Korean adoptees: Ethnic identity development and psychological adjustment. In I. J. Kim (Ed.), Korean-Americans: Past, present, and future (pp. 203-224). Elizabeth, NJ: Hollym International.

${ }^{*}$ Leonardelli, G. J., \& Tormala, Z. L. (2003). The negative impact of perceiving discrimination on collective well-being: The mediating role of perceived ingroup status. European Journal of Social Psychology, 33, 507-514.

*Lewis, T. T., Everson-Rose, S. A., Powell, L. H., Matthews, K. A., Bron, C., Karavolos, K., et al. (2006). Chronic exposure to everyday discrimination and coronary artery calcification in African-American women: The SWAN heart study. Psychosomatic Medicine, 68, 362-368.

*Li, L., \& Moore, D. (1998). Acceptance of disability and its correlates. Journal of Social Psychology, 138(1), 13-25.

'Liebkind, K., \& Jasinskaja-Lahti, I. (1999). The influence of experiences of discrimination on psychological stress: A comparison of seven immigrant groups. Journal of Community \& Applied Social Psychology, $10,1-16$.

'Liebkind, K., Jasinskaja-Lahti, I., \& Solheim, E. (2004). Cultural identity, perceived discrimination, and parental support as determinants of immigrants' school adjustments: Vietnamese youth in Finland. Journal of Adolescent Research, 19, 635-656.

'Lincoln, K. D., Chatters, L. M., Taylor, R. J., \& Jackson, J. S. (2007). Profiles of depressive symptoms among African Americans and Caribbean Blacks. Social Science \& Medicine, 65, 200-213.

Lipsey, M. W., \& Wilson, D. B. (2001). Practical meta-analysis. Thousand Oaks, CA: Sage.

${ }^{*}$ Littrell, J., \& Beck, E. (1999). Perceiving oppression: Relationships with resilience, self-esteem, depressive symptoms, and reliance on God in African-American homeless men. Journal of Sociology and Social Welfare, 26(4), 137-158. 
*'Loo, C. M., Fairbank, J. A., Scurfield, R. M., Ruch, L. O., King, D. W., Adams, L. J., \& Chemtob, C. M. (2001). Measuring exposure to racism: Development and validation of a Race-Related Stressor Scale (RRSS) for Asian American Vietnam veterans. Psychological Assessment, 13(4), 503-520.

Luhtanen, R., \& Crocker, J. (1992). A Collective Self-Esteem Scale: Self-evaluation of one's social identity. Personality and Social Psychology Bulletin, 18(3), 302-318.

*'Major, B., Kaiser, C. R., O’Brien, L. T., \& McCoy, S. K. (2007). Perceived discrimination as worldview threat or worldview confirmation: Implications for self-esteem. Journal of Personality and Social Psychology, 92(6), 1068-1086.

Major, B., Quinton, W. J., \& McCoy, S. K. (2002). Antecedents and consequences of attributions to discrimination: Theoretical and empirical advances. In M. P. Zanna (Ed.), Advances in experimental social psychology (Vol. 34, pp. 251-300). San Diego, CA: Academic Press.

"Major, B., Quinton, W. J., \& Schmader, T. (2003). Attributions to discrimination and self-esteem: Impact of group identification and situational ambiguity. Journal of Experimental Social Psychology, 39, 220231.

*'Mak, A. S., \& Nesdale, D. (2001). Migrant distress: The role of perceived racial discrimination and coping resources. Journal of Applied Social Psychology, 31(12), 2632-2647.

Manuck, S. B., Cohen, S., \& Kaplan, J. R. (1994). Social support and coronary heart disease: Underlying psychological and biological mechanisms. In S. A. Shumaker \& S. M. Czajkowski (Eds.), Social support and cardiovascular disease (pp. 195-221). New York: Plenum Press.

Marsland, A. L., Manuck, S. B., Wood, P., Rabin, B. S., Muldoon, M. F., $\&$ Cohen, S. (1995). $\beta_{2}$-adrenergic receptor density and cardiovascular response to mental stress. Physiology and Behavior, 57(6), 1163-1167.

${ }^{\dagger}$ Martin, J. K., Tuch, S. A., \& Roman, P. M. (2003). Problem drinking patterns among African Americans: The impacts of reports of discrimination, perceptions of prejudice, and "risky" coping strategies. Journal of Health and Social Behavior, 44(3), 408-425.

Mays, V. M., \& Cochran, S. D. (2001). Mental health correlates of perceived discrimination among lesbian, gay, and bisexual adults in the United States. American Journal of Public Health, 91(11), 1869-1876.

Mays, V. M., Cochran, S. D., \& Barnes, N. W. (2007). Race, race-based discrimination, and health outcomes among African Americans. Annиal Review of Psychology, 58, 201-225.

${ }^{\dagger}$ McCoy, S. K., \& Major, B. (2003). Group identification moderates emotional responses to perceived prejudice. Personality and Social Psychology Bulletin, 29(8), 1005-1017.

McEwen, B. S. (1998). Stress, adaptation, and disease: Allostasis and allostatic load. Annals of the New York Academy of Sciences, 840, $33-44$.

McEwen, B. S. (1999). Allostasis and allostatic load: Implications for neuropsychopharmacology. Neuropsychopharmacology, 22(2), 108124

*McNeilly, M. D., Robinson, E. L., Anderson, N. B., Pieper, C. F., Shah, A., Toth, P. S., et al. (1995). Effects of racist provocation and social support on cardiovascular reactivity in African American women. International Journal of Behavioral Medicine, 2(4), 321-338.

*McSwan, K. L. (2000). The impact of sexism on older women's mental and physical health (Doctoral dissertation, Loma Linda University, 2000). Dissertation Abstracts International, 61(6-B), 3323.

Merritt, M. M., Bennett, G., Williams, R. B., Edwards, C. L., \& Sollers, J. J. (2006). Perceived racism and cardiovascular reactivity and recovery to personally relevant stress. Health Psychology, 25(3), 364-369.

${ }^{\top}$ Meyer, I. H. (1995). Minority stress and mental health in gay men. Journal of Health and Social Behavior, 36(1), 38-56.

Miller, G. E., Chen, E., \& Zhou, E. S. (2007). If it goes up, must it come down? Chronic stress and the hypothalamic-pituitary-adrenocortical axis in humans. Psychological Bulletin, 133(1), 25-45.
*Moghaddam, F. M., Taylor, D. M., Ditto, B., Jacobs, K., \& Bianchi, E. (2002). Psychological distress and perceived discrimination: A study of women from India. International Journal of Intercultural Relations, 26 , 381-390.

${ }^{*}$ Moradi, B., \& Hasan, N. T. (2004). Arab American persons' reported experiences of discrimination and mental health: The mediating role of personal control. Journal of Counseling Psychology, 51(4), 418-428.

${ }^{*}$ Moradi, B., \& Risco, C. (2006). Perceived discrimination experiences and mental health of Latino/a American persons. Journal of Counseling Psychology, 53(4), 411-421.

${ }^{*}$ Moradi, B., \& Subich, L. M. (2002). Perceived sexist events and feminist identity development attitudes: Links to women's psychological distress. Counseling Psychologist, 30(1), 44-65.

${ }^{*}$ Moradi, B., \& Subich, L. M. (2003). A concomitant examination of the relations of perceived racist and sexist events to psychological distress for African American women. Counseling Psychologist, 31(4), 451469.

${ }^{*}$ Moradi, B., \& Subich, L. M. (2004). Examining the moderating role of self-esteem in the link between experiences of perceived sexist events and psychological distress. Journal of Counseling Psychology, 51(1), $50-56$.

${ }^{\dagger}$ Mossakowski, K. N. (2003). Coping with perceived discrimination: Does ethnic identity protect mental health? Journal of Health and Social Behavior, 44, 318-331.

*Murry, V. M., Brown, P. A., Brody, G. H., Cutrona, C. E., \& Simons, R. L. (2001). Racial discrimination as a moderator of the links among stress, maternal psychological functioning and family relationships. Journal of Marriage and Family, 63, 915-926.

Naimi, T. S., Lipscomb, L. E., Brewer, R. D., \& Colley, B. G. (2003). Binge drinking in the preconception period and the risk of unintended pregnancy: Implications for women and their children. Pediatrics, 11(5), $1136-1141$

National Center for Health Statistics. (2003). Health, United States, 2003. Hyattsville, MD: Centers for Disease Control and Prevention, National Center for Health Statistics.

National Institutes of Health. (1998). Clinical guidelines on the identification, evaluation, and treatment of overweight and obesity in adults: The evidence report (NIH Publication No. 98-4083). Retrieved from http:// www.nhlbi.nih.gov/guidelines/obesity/ob_gdlns.htm

National Institutes of Health. (2002). Strategic plan for health disparities research, FY 2002-2006. Retrieved from http://obssr.od.nih.gov/ about_obssr/strategic_planning/health_disparities/healthdisp.aspx

Nemeroff, C. B. (1996). The corticotrophin-releasing factor hypothesis of depression: New findings and new directions. Molecular Psychiatry, 1, 336-342.

${ }^{\dagger}$ Noh, S., Beiser, M., Kaspar, V., Hou, F., \& Rummens, J. (1999). Perceived racial discrimination, depression, and coping: A study of Southeast Asian refugees in Canada. Journal of Health and Social Behavior, 40(3), 192-207.

†Noh, S., \& Kaspar, V. (2003). Perceived discrimination and depression: Moderating effects of coping, acculturation, and ethnic support. American Journal of Public Health, 93(2), 232-238.

†Noh, S., Kaspar, V., \& Wickrama, K. A. S. (2007). Overt and subtle racial discrimination and mental health: Preliminary findings for Korean immigrants. American Journal of Public Health, 97(7), 1269-1274.

${ }^{*}$ Nyborg, V. M., \& Curry, J. F. (2003). The impact of perceived racism: Psychological symptoms among African American boys. Journal of Clinical Child and Adolescent Psychology, 32(2), 258-266.

Ockene, I. S., \& Miller, N. H. (1997). Cigarette smoking, cardiovascular disease, and stroke: A statement for healthcare professionals from the American Heart Association. Circulation, 97(9), 3243-3247.

$*^{\dagger}$ Oh, M. Y. (2001). Contingencies of self-esteem: The psychological well-being and impact of perceived experiences of discrimination among Korean Americans (Doctoral dissertation, California School of Profes- 
sional Psychology, 2001). Dissertation Abstracts International, 62(2-B), 1093.

* Pantzer, K., Rajmil, L., Tebé, C., Codina, F., Serra-Sutton, V., Ferrer, M., et al. (2006). Health related quality of life in immigrants and native school aged adolescents in Spain. Journal of Epidemiology and Community Health, 60, 694-698.

Paradies, Y. (2006). A systematic review of empirical research on selfreported racism and health. International Journal of Epidemiology, 35(4), 888-901.

†Pavalko, E. K., Mossakowski, K. N., \& Hamilton, V. J. (2003). Does perceived discrimination affect health? Longitudinal relationships between work discrimination and women's physical and emotional health. Journal of Health and Social Behavior, 44, 18-33.

${ }^{\dagger}$ Pek, J. (2007). Race, discrimination, and ambulatory cardiovascular measure. Unpublished manuscript.

*Peters, R. M. (2004). Racism and hypertension among African Americans. Western Journal of Nursing Research, 26(6), 612-631.

* Peters, R. M. (2006). The relationship of racism, chronic stress emotions, and blood pressure. Journal of Nursing Scholarship, 3, 234-240.

Phinney, J. (1992). The Multigroup Ethnic Identity Measure: A new scale for use with adolescents and young adults from diverse groups. Journal of Adolescent Research, 7, 156-176.

* Pieterse, A. L., \& Carter, R. T. (2007). An examination of the relationship between general life stress, racism-related stress, and psychological health among Black men. Journal of Counseling Psychology, 54(1), 101-109.

TPortes, P. R., \& Zady, M. F. (2002). Self-esteem in the adaptation of Spanish-speaking adolescents: Role of immigration, family conflict, and depression. Hispanic Journal of Behavioral Sciences, 24(3), 296-318.

*Poston, W. S. C., Pavlik, V. N., Hyman, D. J., Ogbonnaya, K., Hanis, C. L., Haddock, C. K., et al. (2001). Genetic bottlenecks, perceived racism and hypertension risk among African Americans and firstgeneration African immigrants. Journal of Human Hypertension, 15, 341-351.

* Prelow, H. M., Mosher, C. E., \& Bowman, M. A. (2006). Perceived racial discrimination, social support, and psychological adjustment among African American college students. Journal of Black Psychology, 32(4), 442-454.

Raison, C. L., \& Miller, A. H. (2003). When not enough is too much: The role of insufficient glucocorticoid signaling in the pathophysiology of stress-related disorders. American Journal of Psychiatry, 160, 15541565.

* Redman, T., \& Snape, E. (2006). The consequences of perceived age discrimination amongst older police officers: Is social support a buffer? British Journal of Management, 17, 167-175.

${ }^{\dagger}$ Ren, X. S., Amick, B. C., \& Williams, D. R. (1999). Racial/ethnic disparities in health: The interplay between discrimination and socioeconomic status. Ethnicity \& Disease, 9(2), 151-165.

* Rivera, F. I. (2003). Exploring the pathways that mediate the relationship between acculturation and depression among Latinos (Doctoral dissertation, University of Nebraska, 2003). Dissertation Abstracts International, 64(5-A), 1859.

Robles, T. F., Glaser, R., \& Kiecolt-Glaser, J. K. (2005). Out of balance: A new look at chronic stress, depression, and immunity. Current Directions in Psychological Science, 14(2), 111-115.

* Rodriguez, M. S. (2004). Effects of perceived discrimination on mental health: Exploring intervening relationships (Doctoral dissertation, Kent State University, 2004). Dissertation Abstracts International, 65(9-A), 3589 .

*'Romero, A. J., \& Roberts, R. E. (2003). The impact of multiple dimensions of ethnic identity on discrimination and adolescents' self-esteem. Journal of Applied Social Psychology, 33(11), 2288-2305.

${ }^{\dagger}$ Rumbaut, R. G. (1994). The crucible within: Ethnic identity, self-esteem, and segmented assimilation among children of immigrants. International Migration Review, 28(4), 748-794.

${ }^{\dagger}$ Rusch, N., Lieb, K., Bohus, M., \& Corrigan, P. W. (2006). Self-stigma, empowerment, and perceived legitimacy of discrimination among women with mental illness. Psychiatric Services, 57(3), 399-402.

Ryan, A., Gee, G. C., \& Griffith, D. M. (2007). The effects of perceived discrimination and patient-physician racial and gender concordance on diabetes management. Unpublished manuscript.

${ }^{*}$ Ryan, A. M., Gee, G. C., \& Laflamme, D. F. (2006). The association between self-reported discrimination, physical health and blood pressure: Findings from African Americans, Black immigrants, and Latino immigrants in New Hampshire. Journal of Health Care for the Poor and Underserved, 17, 116-132.

${ }^{\dagger}$ Ryff, C. D., Keyes, C. L. M., \& Hughes, D. L. (2003). Status inequalities, perceived discrimination, and eudaimonic well-being: Do the challenges of minority life hone purpose and growth? Journal of Health and Social Behavior, 44(3), 275-291.

'Sabik, N. J., \& Tylka, T. L. (2006). Do feminist identity styles moderate the relation between perceived sexist events and disordered eating? Psychology of Women Quarterly, 30, 77-84.

Salgado de Snyder, V. N. (1987). Factors associated with acculturative stress and depressive symptomology among married Mexican immigrant women. Psychology of Women Quarterly, 11, 475-488.

${ }^{*}$ Sanders Thompson, V. L. (2006). Coping responses and the experience of discrimination. Journal of Applied Social Psychology, 36(5), 1198 1214.

†Sandfort, T. G., Melendez, R. M., \& Diaz, R. M. (2007). Gender nonconformity, homophobia, and mental distress in Latino gay and bisexual men. Journal of Sex Research, 44(2), 181-189.

*Schmitt, M. T., Branscombe, N. R., Kobrynowica, D., \& Owen, S. (2002). Perceiving discrimination against one's gender group has different implications for well-being in women and men. Personality and Social Psychology Bulletin, 28, 197-210.

${ }^{*}{ }^{\dagger}$ Schmitt, M. T., Branscombe, N. R., \& Postmes, T. (2003). Women's emotional responses to the pervasiveness of gender discrimination. European Journal of Social Psychology, 33, 297-312.

${ }^{*}$ 'Schneider, K. T., Hitlan, R. T., \& Radhakrishnan, P. (2000). An examination of the nature and correlates of ethnic harassment experiences in multiple contexts. Journal of Applied Psychology, 85(1), 3-12.

Schulkin, J., McEwen, B. S., \& Gold, P. W. (1994). Allostasis, amygdala, and anticipatory angst. Neuroscience and Biobehavioral Reviews, 18, 385-396.

Schulz, A. J., Gravlee, C. C., Williams, D. R., Israel, B. A., Mentz, G., \& Rowe, Z. (2006). Discrimination, symptoms of depression, and selfrated health among African American women in Detroit: Results from a longitudinal analysis. American Journal of Public Health, 96(7), 12651270.

${ }^{\dagger}$ Schulz, A., Israel, B., Williams, D., Parker, E., Becker, A., \& James, S. (2000). Social inequalities, stressors and self reported health status among African American and White women in the Detroit metropolitan area. Social Science \& Medicine, 51, 1639-1653.

Seeman, T. E., Singer, B. H., Rowe, J. W., Horwitz, R. I., \& McEwen, B. S. (1997). Price of adaptation-Allostatic load and its health consequences: MacArthur studies of successful aging. Archives of Internal Medicine, 157, 2259-2268.

Seifert, K., Bowman, P. J., Heflin, C. M., Danziger, S., \& Williams, D. R. (2000). Social and environmental predictors of maternal depression in current and recent welfare recipients. American Journal of Orthopsychiatry, 70(4), 510-522.

*Sellers, R. M., Caldwell, C. H., Schmeelk-Cone, K. H., \& Zimmerman, M. A. (2003). Racial identity, racial discrimination, perceived stress, and psychological distress among African American young adults. Journal of Health and Social Behavior, 44(3), 302-317.

${ }^{*}$ Sellers, R. M., Copeland-Linder, N., Martin, P. P., \& Lewis, R. L. 
(2006). Racial identity matters: The relationship between racial discrimination and psychological functioning in African American adolescents. Journal of Research on Adolescence, 16(2), 187-216.

Sellers, R. M., Rowley, S. A. J., Chavous, T. M., Shelton, J. N., \& Smith, M. A. (1997). Multidimensional Inventory of Black Identity: A preliminary investigation of reliability and construct validity. Journal of Personality and Social Psychology, 73(4), 805-815.

${ }^{*}$ Sellers, R. M., \& Shelton, N. J. (2003). The role of racial identity in perceived racial discrimination. Journal of Personality and Social Psychology, 84(5), 1079-1092.

*'Shrake, E. K., \& Rhee, S. (2004). Ethnic identity as a predictor of problem behaviors among Korean American adolescents. Adolescence, 39(155), 601-622.

*'Simons, R. L., Chen, Y., Stewart, E. A., \& Brody, G. H. (2003). Incidents of discrimination and risk for delinquency: A longitudinal test of strain theory with an African American sample. Justice Quarterly, 20(4), 827-854.

*'Simons, R. L., Murry, V., McLoyd, V., Lin, K.-H., Cutrona, C., \& Conger, R. D. (2002). Discrimination, crime, ethnic identity, and parenting as correlates of depressive symptoms among African American children: A multilevel analysis. Development and Psychopathology, 14, 371-393.

*'Simons, R. L., Simons, L. G., Burt, C. H., Drummond, H., Stewart, E., Brody, G. H., et al. (2006). Supportive parenting moderates the effect of discrimination upon anger, hostile view of relationships, and violence among African American boys. Journal of Health and Social Behavior, 47, 373-389.

Smart Richman, L., Kaufman, E. A., \& Genderson, A. (2008, February). The effects of past discrimination on everyday emotional and physiological responses to social interaction. Poster session presented at the annual meeting of the Society for Personality and Social Psychology, Albuquerque, NM.

${ }^{\dagger}$ Smart Richman, L., Pek, J., Malone, P. S., Siegler, I. C., \& Williams, R. B. (2008). Perceived discrimination and depressive symptoms: An examination of underlying variables. Manuscript submitted for publication.

Smart Richman, L., Pek, J., \& Pascoe, E.A. (2008). The effects of race, perceived discrimination, and time on ambulatory blood pressure modeled over a 24-hour period. Manuscript submitted for publication.

Smith, G. D., Ben-Shlomo, Y., Beswick, A., Yarnell, J., Lightman, S., \& Elwood, P. (2005). Cortisol, testosterone, and coronary heart disease: Prospective evidence from the Caerphilly Study. Circulation, 112, 332340.

Smith, G. S., Branas, C. C., \& Miller, T. R. (1999). Fatal nontraffic injuries involving alcohol: A meta-analysis. Annals of Emergency Medicine, $33(6), 659-668$.

*'Smith, J. L., Kausar, R., \& Holt-Lunstad, J. (2007). Stigma consciousness in the classroom: A comparison of Pakistani women's motivation and well-being in science and non-science fields of study. Sex Roles, 57, 3-13.

*Soriano, F. I., \& Ramirez, A. (1991). Unequal employment status and ethnicity: Further analysis of the USPI-ESPI model. Hispanic Journal of Behavioral Sciences, 13(4), 391-400.

*'Steffen, P. R., McNeilly, M., Anderson, N., \& Sherwood, A. (2003). Effects of perceived racism and anger inhibition on ambulatory blood pressure in African Americans. Psychosomatic Medicine, 65, 746-750.

Strauman, T. J. (2002). Self-regulation and depression. Self and Identity, 1, $151-157$.

${ }^{\dagger}$ Stuber, J., Galea, S., Ahern, J., Blaney, S., \& Fuller, C. (2003). The association between multiple domains of discrimination and selfassessed health: A multilevel analysis of Latinos and Blacks in four low-income New York City neighborhoods. Health Services Research, 36(6), 1735-1759.

${ }^{\dagger}$ Swim, J. K., Hyers, L. L., Cohen, L. L., \& Ferguson, M. J. (2001). Everyday sexism: Evidence for its incidence, nature, and psychological impact from three daily diary studies. Journal of Social Issues, 57(4), $31-53$.

*Szalacha, L. A., Coll, C. G., Alarcón, O., Fields, J. P., \& Ceder, I. (2003). Discrimination and Puerto Rican children's and adolescents' mental health. Cultural Diversity and Ethnic Minority Psychology, 9(2), 141155 .

${ }^{\dagger}$ Szymanski, D. M. (2005). Heterosexism and sexism as correlates of psychological distress in lesbians. Journal of Counseling \& Development, 83, 355-360.

*†Taylor, J., \& Turner, R. J. (2002). Perceived discrimination, social stress, and depression in the transition to adulthood: Racial contrasts. Social Psychology Quarterly, 65(3), 213-225.

Taylor, T. R., Williams, C. D., Makambi, K. H., Mouton, C., Harrell, J. P., Cozier, Y., et al. (2007). Racial discrimination and breast cancer incidence in US Black women. American Journal of Epidemiology, 166(1), $46-54$.

†Thomas, K. S., Nelesen, R. A., Malcarne, V. L., Ziegler, M. G., \& Dimsdale, J. E. (2006). Ethnicity, perceived discrimination, and vascular reactivity to phenylephrine. Psychosomatic Medicine, 68, 692-697.

*†Thompson, H. S. (1999). The relationship between chronic acculturative/ racial stressors and cardiovascular outcomes in African American adults: Is cardiovascular reactivity a mediating variable? (Doctoral dissertation, University of Pittsburgh, 1999). Dissertation Abstracts International, 60(9-B), 4914.

'Thompson, V. L. S., Noel, J. G., \& Campbell, J. (2004). Stigmatization, discrimination, and mental health: The impact of multiple identity status. American Journal of Orthopsychiatry, 74(4), 529-544.

Treiber, F. A., Kamarck, T., Schneiderman, N., Sheffield, D., Kapuku, G., \& Taylor, T. (2003). Cardiovascular reactivity and development of preclinical and clinical disease states. Psychosomatic Medicine, 65, $45-62$.

*†Troxel, W. M., Matthews, K. A., Bromberger, J. T., \& Sutton-Tyrrell, K. (2003). Chronic stress burden, discrimination, and subclinical carotid artery disease in African American and Caucasian women. Health Psychology, 22(3), 300-309.

'Turner, R. J., \& Avison, W. R. (2003). Status variations in stress exposure: Implications for the interpretation of research on race, socioeconomic status, and gender. Journal of Health and Social Behavior, 44(4), $488-505$.

${ }^{*}{ }^{\dagger}$ Umaña-Taylor, A. J., \& Updegraff, K. A. (2007). Latino adolescents' mental health: Exploring the interrelations among discrimination, ethnic identity, cultural orientation, self-esteem, and depressive symptoms. Journal of Adolescence, 30, 549-567.

Uno, H., Ross, T., Else, J., Suleman, M., \& Sapolsky, R. (1989). Hippocampal damage associated with prolonged and fatal stress in primates. Journal of Neuroscience, 9, 1709-1711.

U.S. Department of Health and Human Services. (2004). The health consequences of smoking: A report of the surgeon general. Retrieved from http://www.surgeongeneral.gov/library/smokingconsequences/

${ }^{*}$ Utsey, S. O., Chae, M. H., Brown, C. F., \& Kelly, D. (2002). Effect of ethnic group membership on ethnic identity, race-related stress, and quality of life. Cultural Diversity and Ethnic Minority Psychology, 8(4), $366-377$

*Utsey, S. O., \& Hook, J. N. (2007). Heart rate variability as a physiological moderator of the relationship between race-related stress and psychological distress in African Americans. Cultural Diversity and Ethnic Minority Psychology, 13(3), 250-253.

*†Utsey, S. O., Lanier, Y., Williams, O., III, Bolden, M., \& Lee, A. (2006). Moderator effects of cognitive ability and social support on the relation between race-related stress and quality of life in a community sample of Black Americans. Cultural Diversity and Ethnic Minority Psychology, 12(2), 334-346

${ }^{*}$ Utsey, S. O., \& Payne, Y. (2000). Psychological impacts of racism in a 
clinical versus normal sample of African American men. Journal of African American Men, 5(3), 57-72.

* Utsey, S. O., Payne, Y. A., Jackson, E. S., \& Jones, A. M. (2002). Race-related stress, quality of life indicators, and life satisfaction among elderly African Americans. Cultural Diversity and Ethnic Minority Psychology, 8(3), 224-233.

* Verkuyten, M., \& Nekuee, S. (1999). Subjective well-being, discrimination and cultural conflict: Iranians living in the Netherlands. Social Indicators Research, 47, 281-306.

*Verkuyten, M., \& Neukee, S. (2001). Self-esteem, discrimination, and coping among refugees: The moderating role of self-categorization. Journal of Applied Social Psychology, 31(5), 1058-1075.

* Verkuyten, M., \& Thijs, J. (2004). Psychological disidentification with the academic domain among ethnic minority adolescents in the Netherlands. British Journal of Educational Psychology, 74, 109-125.

*Vines, A. I., Baird, D. D., Stevens, J., Hertz-Picciotto, I., Light, K. C., \& McNeilly, M. (2007). Associations of abdominal fat with perceived racism and passive emotional responses to racism in African American women. American Journal of Public Health, 97(3), 526-530.

*广Waldo, C. R. (1999). Working in a majority context: A structural model of heterosexism as minority stress in the workplace. Journal of Counseling Psychology, 46(2), 218-232.

Walker, E. F., \& Diforio, D. (1997). Schizophrenia: A neural diathesisstress model. Psychological Review, 104, 667-685.

†Wamala, S., Merlo, J., Boström, G., \& Hogstedt, C. (2008). Perceived discrimination, socioeconomic disadvantage and refraining from seeking medical treatment in Sweden. Journal of Epidemiology and Community Health, 61, 409-415.

Wechsler, H., Davenport, A., Dowdall, G., Moeykens, B., \& Castillo, S. (1994). Health and behavioral consequences of binge drinking in college. Journal of the American Medical Association, 272(21), 16721677.

${ }^{*}$ Whitbeck, L. B. (2001). Perceived discrimination and early substance abuse among African Indian children. Journal of Health and Social Behavior, 42(4), 405-424

*'Whitbeck, L. B., Chen, X., Hoyt, D. R., \& Adams, G. W. (2004). Discrimination, historical loss and enculturation: Culturally specific risk and resiliency factors for alcohol abuse among American Indians. Journal of Studies on Alcohol, 65(4), 409-418.

*广Whitbeck, L. B., McMorris, B. J., Hoyt, D. R., Stubben, J. D., \& LaFramboise, T. (2002). Perceived discrimination, traditional practices, and depressive symptoms among American Indians in the upper Midwest. Journal of Health and Social Behavior, 43(4), 400-418.

Williams, D. R., \& Mohammed, S. A. (2009). Discrimination and racial disparities in health: Evidence and needed research. Journal of Behavioral Medicine, 32, 20-47.

Williams, D. R., Neighbors, H. W., \& Jackson, J. S. (2003). Racial/ethnic discrimination and health: Findings from community studies. American Journal of Public Health, 93(2), 200-208.

${ }^{\dagger}$ Williams, D. R., Spencer, M. S., \& Jackson, J. S. (1999). Race, stress, and physical health: The role of group identity. In R. J. Contrada \& R. D. Ashmore (Eds.), Self, social identity, and physical health: Interdisciplinary explorations (pp. 71-100). New York: Oxford University Press.

Williams, D. R., \& Williams-Morris, R. (2000). Racism and mental health: The African American experience. Ethnicity \& Health, 5(3-4), 243268.

${ }^{\dagger}$ Williams, D. R., Yu, Y., Jackson, J. S., \& Anderson, N. B. (1997). Racial differences in physical and mental health: Socio-economic status, stress and discrimination. Journal of Health Psychology, 2(3), 335-351.

${ }^{\dagger}$ Wolitski, R. J., Pais, S. L., Kidder, D. P., Courtenay-Quirk, C., \& Holtgrave, D. R. (2007). Stigma is associated with poor mental and physical health among homeless/unstably housed persons living with HIV. Atlanta, GA: Centers for Disease Control and Prevention, Division of HIV/AIDS Prevention.

*Yen, I. H., Ragland, D. R., Grenier, B. A., \& Fisher, J. M. (1999). Workplace discrimination and alcohol consumption: Findings from the San Francisco Muni Health and Safety Study. Ethnicity \& Disease, 9(1), $70-80$.

${ }^{*}$ Yoo, H. C., \& Lee, R. M. (2005). Ethnic identity and approach-type coping as moderators of the racial discrimination/well-being relation in Asian Americans. Journal of Counseling Psychology, 52(4), 497-506.

†Yoshikawa, H., Wilson, P. D., Chae, D. H., \& Cheng, J. (2004). Do family and friendship networks protect against the influence of discrimination on mental health and HIV risk among Asian and Pacific Islander gay men? AIDS Education and Prevention, 16(1), 84-100.

${ }^{*}$ Zakalik, R. A., \& Wei, M. (2006). Adult attachment, perceived discrimination based on sexual orientation, and depression in gay males: Examining the mediation and moderation effects. Journal of Counseling Psychology, 53(3), 302-313.

*'Zamboni, B. D., \& Crawford, I. (2007). Minority stress and sexual problems among African-American gay and bisexual men. Archives of Sexual Behavior, 36, 569-578.

*Zucker, A. N., \& Landry, L. J. (2007). Embodied discrimination: The relation of sexism and distress to women's drinking and smoking behaviors. Sex Roles, 56, 193-203.

Received May 3, 2008

Revision received March 3, 2009

Accepted March 20, 2009 